\title{
PIM-1-specific mAb suppresses human and mouse tumor growth by decreasing PIM-1 levels, reducing Akt phosphorylation, and activating apoptosis
}

Xiu Feng Hu, ${ }^{1}$ Jie Li,, ${ }^{1,2}$ Scott Vandervalk, ${ }^{1}$ Zeping Wang, ${ }^{3}$ Nancy S. Magnuson, ${ }^{3}$ and Pei Xiang Xing ${ }^{1}$

${ }^{1}$ Cancer Immunotherapy Laboratory, Burnet Institute Incorporating Austin Research Institute, Heidelberg, Victoria, Australia. 2Department of Hematology, Qilu Hospital, Shandong University, Jinan, People's Republic of China. ${ }^{3}$ School of Molecular Biosciences, Washington State University, Pullman, Washington, USA.

\begin{abstract}
Provirus integration site for Moloney murine leukemia virus (PIM1) is a proto-oncogene that encodes a serine/ threonine kinase with multiple cellular functions. Overexpression of PIM-1 plays a critical role in progression of prostatic and hematopoietic malignancies. Here we describe the generation of a mAb specific for GST-PIM-1, which reacted strongly with most human and mouse cancer tissues and cell lines of prostate, breast, and colon origin but only weakly (if at all) with normal tissues. The mAb binds to PIM-1 in the cytosol and nucleus as well as to PIM-1 on the surface of human and murine cancer cells. Treatment of human and mouse prostate cancer cell lines with the PIM-1-specific mAb resulted in disruption of PIM-1/Hsp90 complexes, decreased PIM-1 and Hsp90 levels, reduced Akt phosphorylation at Ser473, reduced phosphorylation of Bad at Ser112 and Ser136, and increased cleavage of caspase-9, an indicator of activation of the mitochondrial cell death pathway. The $\mathrm{mAb}$ induced cancer cell apoptosis and synergistically enhanced antitumor activity when used in combination with cisplatin and epirubicin. In tumor models, the PIM-1-specific mAb substantially inhibited growth of the human prostate cancer cell line DU145 in SCID mice and the mouse prostate cancer cell TRAMP-C1 in $\mathrm{C} 57 \mathrm{BL} / 6$ mice. These findings are important because they provide what we believe to be the first in vivo evidence that treatment of prostate cancer may be possible by targeting PIM-1 using an Ab-based therapy.
\end{abstract}

\section{Introduction}

Provirus integration site for Moloney murine leukemia virus (PIM-1), a proto-oncogene encoding a serine/threonine protein kinase, has multiple cellular functions involved in cell survival, proliferation, differentiation, apoptosis, and tumorigenesis $(1,2)$. Overexpression of PIM-1 is linked to the development and progression of several hematopoietic malignancies and prostate cancer $(3,4)$. Pim-1 was originally identified as a preferential proviral integration site in Moloney murine leukemia virus-induced T cell lymphomas (5) and the first described member of the Pim family, which includes 2 other serine/threonine kinases Pim- 2 and Pim-3 (6). The murine Pim 1 gene encodes 2 isoforms with molecular weights of 33 and $44 \mathrm{kDa}$, respectively (7). There is $94 \%$ identity between human and murine Pim-1 (8). The translation of the $44-\mathrm{kDa}$ Pim-1 in mice is initiated at a nonconventional start codon CUG, which is not present in an optimal Kozak consensus context in human PIM1 gene (7). However, recent studies show that human PIM1 gene, like its murine counterpart, encodes 2 isoforms with molecular weights of 33 and $44 \mathrm{kDa}$, respectively $(7,9)$. In particular, the 44-kDa PIM-1 is translated efficiently and significantly upregulated in human prostate cancer cell lines as well as human prostate tumors (9). PIM-1 kinase activity is found in the cytoplasmic and nuclear frac-

Conflict of interest: The authors have declared that no conflict of interest exists.

Nonstandard abbreviations used: $\mathrm{Bad}, \mathrm{Bcl}-\mathrm{xL} / \mathrm{Bcl}-2$-associated death promoter; GST, glutathione-S-transferase; mIgM, normal mouse IgM; MUC1, human mucin 1; PIM1, provirus integration site for Moloney murine leukemia virus. Citation for this article: J. Clin. Invest. 119:362-375 (2009). doi:10.1172/JCI33216. tions as well as in the membrane of the cells $(7,9)$. The subcellular localization of the 44-kDa PIM- 1 is primarily on the plasma membrane, while the $33-\mathrm{kDa}$ isoform is present in both the cytosol and nucleus, suggesting that these 2 isoforms may regulate distinct signaling pathways in cancer cells (9).

During embryonic development, PIM-1 is highly and specifically expressed in liver, spleen and bone marrow in typical hematopoietic progenitors (4), neonatal heart (10), central nervous system at specific stages (11), and mammary gland (12). In contrast, PIM-1 is only slightly expressed in circulating granulocytes at the adult stage (4). The expression of Pim-1 during development and its subsequent shut off in adult tissues suggests that its untimely overexpression may contribute to malignant transformation. Enforced expression of Pim-1 in transgenic mice leads to enhanced lymphoproliferation and inhibition of apoptosis (13). Increased expression of Pim-1 in lymphoid cells by transgenesis underscored its oncogenic potential (7). PIM-1 overexpression in prostate cancer was identified by cDNA microarray and immunochemical staining (3). Upregulation of PIM-1 was demonstrated in premalignant lesion and prostatic adenocarcinoma compared with benign prostatic epithelium $(3,14)$. Altered expression of PIM-1 kinase correlated significantly with poor outcome (15). PIM-1 may participate in deregulation of cell growth in prostate cancer through hormone-independent activation of androgen receptor, a typical characteristic of advanced prostate cancer that offers poor prognosis (16). Overexpression of PIM-1 was also found in oral squamous cell carcinoma (17) and in various human leukemias such as B cell lymphomas, erythroleukemias, and acute myelogenous leukemia 

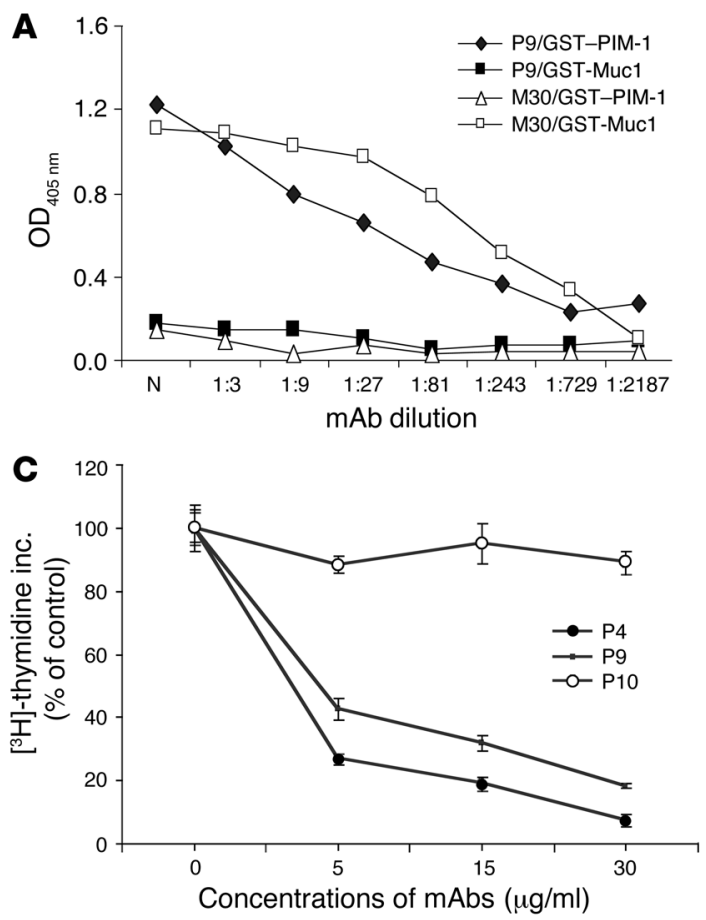

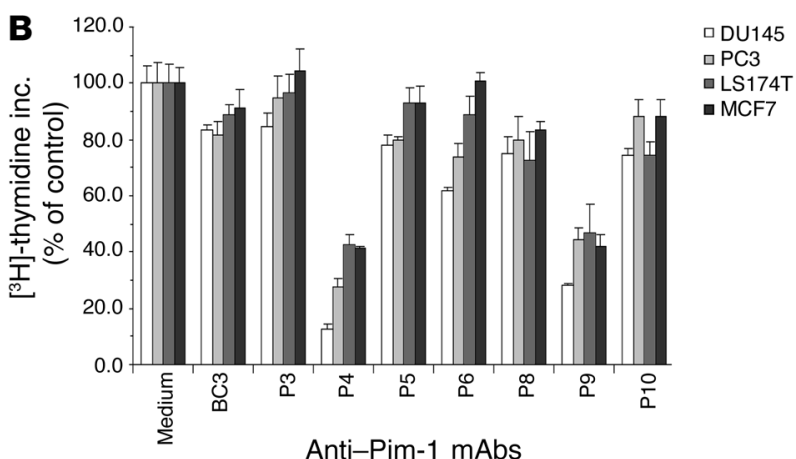

Anti-Pim-1 mAbs

\section{Figure 1}

Characterization of anti-PIM-1 mAb. (A) Specific binding of mAb P9 with GST-PIM-1 was shown with ELISA, using tissue culture supernatant of mAb. Recombinant GST-Muc1 and anti-murine Muc1 mAb M30 (IgM subclass) were used as antigen and isotype matched control, respectively. (B) Inhibition of cancer cell growth using mAb P3, P4, P5, P6, P8, P9, and P10, at $10 \mu \mathrm{g} / \mathrm{ml}$ for 72 hours of incubation, is shown as percentage of control in $\left[{ }^{3} \mathrm{H}\right]$-thymidine incorporation (inc.) of prostate (DU145, PC3), colon (LS174T), and breast (MCF7) cancer cells. Anti-MUC1 mAb BC3 was used as a control. Columns show means of triplicate experiments as percentages compared with medium control; bars represent \pm SD. (C) Percentage of control in $\left[{ }^{3} \mathrm{H}\right]$-thymidine incorporation of DU145 prostate cancer cells in the presence of mAb P4, P9, and P10 at concentrations of $5-30 \mu \mathrm{g} / \mathrm{ml}$ for 72 hours. Values (mean $\pm \mathrm{SD}$ ) represent the mean value derived from triplicate experiments.

$(4,18,19)$. PIM-1 was reported to cooperate with the antiapoptotic protein A1 in BCR/ABL-mediated leukemogenesis (20). These observations further support the hypothesis that PIM-1 is important in prostatic and hematopoietic carcinogenesis and tumor progression.

The expression of PIM-1 is induced by multiple cytokines, including SCF, G-CSF, IFN- $\gamma$, GM-CSF, IL-2, -3, -6, -7, and prolactin, through activation JAK/STAT signaling pathways (2). In addition, PIM-1 itself can negatively regulate the JAK/STAT pathway by binding to SOCS proteins, a group of negative regulators of STAT activity (21). PI3K and its downstream effector AKT are also involved in regulation of Pim-1 expression $(22,23)$. Hsp90 is coordinately regulated with PIM-1 and is responsible for the stabilization and function of PIM-1 $(24,25)$. PIM-1 is able to phosphorylate itself $(26,27)$ through its recently identified novel autophosphorylation site that diverges from its consensus phosphorylation motif (28). Several substrates of PIM-1 have been identified, including p21Cip1/WAF1 (29, 30), Cdc25A (31), PTPU2 (32), NuMA (33), C-TAK1 (34), and Cdc25C (35), indicating PIM-1 is involved in the cell proliferation at both $\mathrm{G}_{1} / \mathrm{S}$ and $\mathrm{G}_{2} / \mathrm{M}$ transition. PIM-1 also contributes to the regulation of cell apoptosis and antiapoptotic activity $(32,36,37)$. A direct effect of PIM-1 on the antiapoptotic pathway was demonstrated by its association with and phosphorylation of $\mathrm{Bcl}-\mathrm{xL} / \mathrm{Bcl}-2$-associated death promoter $(\mathrm{Bad})$, which is a proapoptotic member of the Bcl-2 family and capable of forming heterodimers with $\mathrm{Bcl}-2$ or $\mathrm{Bcl}-\mathrm{xL}$. This association releases $\mathrm{BAX}$ and $\mathrm{BAK}$ from $\mathrm{Bcl}-2$ and $\mathrm{Bcl}-\mathrm{xL}$ heterodimers and allows $\mathrm{BAX}$ and BAK to aggregate in the mitochondrion membrane, leading to release of cytochrome $\mathrm{c}$ and activation of caspase-9 (38). PIM-1 binds, phosphorylates, and inactivates Bad, both in vitro and in vivo, on Ser112, a gatekeeper residue for its activation and apoptotic resistance $(39,40)$. PIM-1 also phosphorylates Bad at Ser136 and Ser155, which assists in inactivation of Bad proapoptotic activity $(40,41)$. Recent studies demonstrated that the $44 \mathrm{kDa}$ plays a more prominent role in antiapoptosis signaling and promotes drug resistant activity in the cancer cells $(9,42)$. The findings support the idea that PIM-1 is a potential tumor target for therapeutic development (43). In this paper, we provide the first evidence to our knowledge that the anti-PIM-1-specific mAb generated in our laboratory can directly bind to the cell surface-associated PIM-1, inhibit tumor growth in vitro and in vivo, and synergistically enhance cytotoxic effect in combination with drugs. The antitumor activity of the mAb was correlated with decreased PIM-1 expression, Akt phosphorylation, and dephosphorylated Bad as well as activation of caspase-9, an indicator of activation of mitochondrial apoptosis pathway.

\section{Results}

Characterization of PIM-1 mAb. A number of hybridomas were generated after fusion of murine myeloma cells NS1 with spleen cells from the mouse immunized by glutathione-S-transferase-PIM-1 (GST-PIM-1). Ten anti-PIM-1 mAbs producing hybridoma 

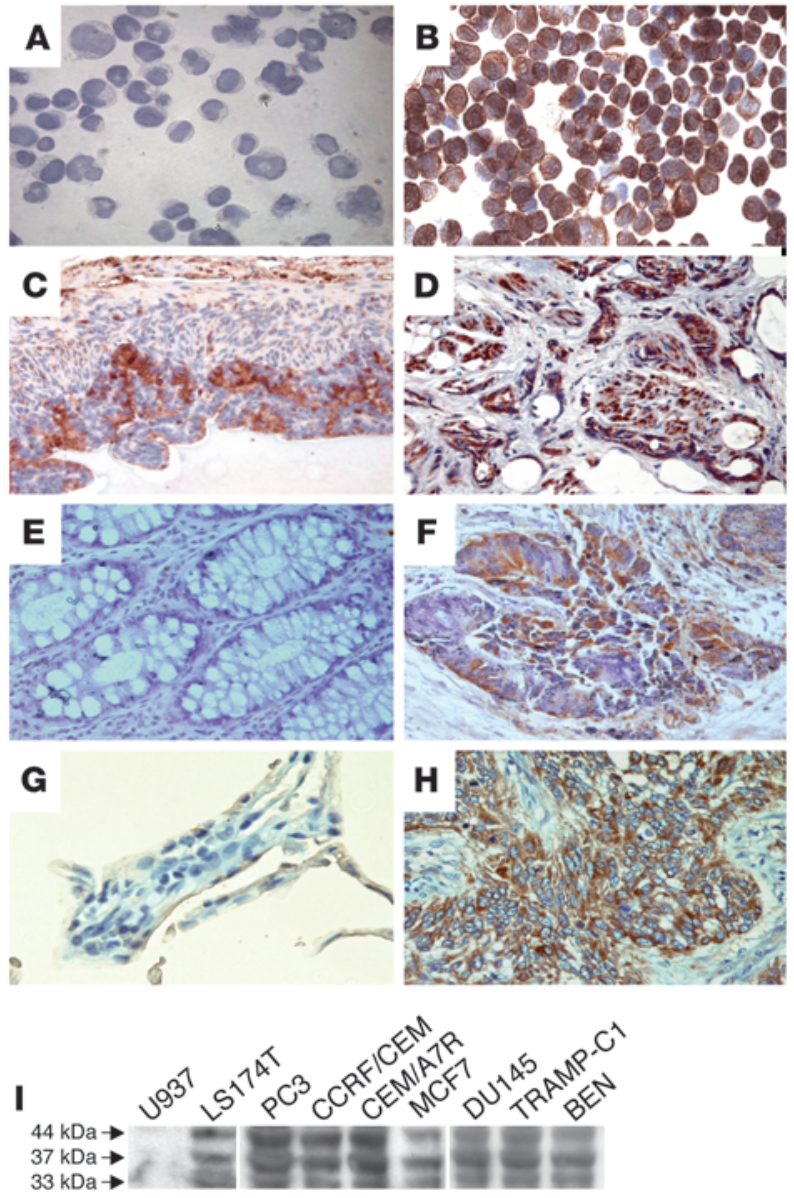

clones (P1-P10) were identified by ELISA. The mAbs specifically reacted with GST-PIM-1 and did not react with irrelevant murine GST-Muc1, while anti-Muc1 mAb M30 had a reaction with GSTMuc1 but not with GST-PIM-1 (Figure 1A). The mAbs were next screened for growth inhibitory activity using $\left[{ }^{3} \mathrm{H}\right]$-thymidine incorporation assay in human prostate cancer DU145 and PC3, colon cancer LS174T, and breast cancer MCF7 cell lines (Figure 1B). At the concentration of $10 \mu \mathrm{g} / \mathrm{ml}, \mathrm{P} 4$ and P9 showed more than $55 \%$ inhibition of proliferation, while other anti-PIM- $1 \mathrm{mAbs}$ showed less than $30 \%$ inhibition of proliferation (Figure 1B). BC3, an anti-human MUC1 mAb (IgM subclass), was used as control $\mathrm{mAb}$, showed around $10 \%$ of cell growth inhibition in the tested cancer cell lines (Figure 1B). The inhibition was dose dependent, as it was increased from $57 \%$ and $73 \%$ to $82 \%$ and $93 \%$ when the concentrations of P4 and P9 were increased from 5 to $30 \mu \mathrm{g} / \mathrm{ml}$, respectively, in DU145 cells (Figure 1C). In contrast, P10, a representative of noninhibitory $\mathrm{mAb}$ at $30 \mu \mathrm{g} / \mathrm{ml}$, only inhibited $9 \%$ of $\left[{ }^{3} \mathrm{H}\right]$-thymidine incorporation of DU145 cells. The results indicated that P4 and P9 induced a specific inhibitory effect on cancer cell growth. The specificity of $\mathrm{mAb}$ P9 to PIM-1 has also been verified in previous studies $(25,33-35)$ in which P9 immunoprecipitated a protein of the correct molecular weight from cells transfected with a FLAG-tagged PIM-1 but not from the cells transfected with vector only. The precipitated molecule was reactive with anti-FLAG M2. The molecule, immunoprecipitated by P9 in K562, U937 (TPA treated), or Hela cells, was also detected by mAb 19F7, a commercially obtained anti-PIM-1 mAb or polyclonal anti-PIM-1 Ab.

\section{Figure 2}

Immunohistochemical staining and Western blot of P9 in tissues and cell lines. Immunohistochemical staining of normal mouse IgM (A) and P9 (B) in prostate cancer cells DU145, and immunoperoxidase staining of P9 in formalin-fixed tissues of human (C) and mouse (D) prostate cancers, normal human colon $(\mathbf{E})$ and colon cancer $(\mathbf{F})$, and normal lung $(\mathbf{G})$ and lung cancer $(\mathbf{H})$, respectively, are shown. Original magnification, $\times 400$. (I) The western blot analysis of P9 binding to PIM-1 protein in cancer cell lysates shows that P9 reacted with 44-, 33-, and 37-kDa isoforms of PIM-1 in various cancer cell lines, including prostate (PC3, DU145), breast (MCF7), colon (LS174T), and lung cancer (Ben), leukemia (U937, CCRF/CEM, CEM/A7R), and murine prostate cancer (TRAMP-C1). The cell lysates were run on $4 \%-12 \%$ gradient SDS-PAGE gel. The samples were run on same gel but were noncontiguous as indicated by the white lines.

These results strongly indicated that P9 specifically reacted with PIM-1. In this study, we focused on P9 and P4 to investigate their potential inhibitory effects on cancer therapy and on the possible mechanisms involved.

Reaction of PIM-1 mAb with cancer cells and tissues. Immunoperoxidase staining demonstrated that P9 specifically reacted with DU145 cells, while normal mouse IgM did not (Figure 2, A and B). The staining was mainly located in cytosol and nucleus (Figure 2B). Similar patterns of P9 staining were observed in human PC3, CEM/A7R, and MCF7 cancer cell lines, and murine TRAMP-C1 prostate cancer (data not shown). Further examination of P9 in various human cancer tissues demonstrated that $\mathrm{P} 9$ reacted with most tested formalin-fixed prostate (Figure 2C), colon (Figure 2F), lung (Figure $2 \mathrm{H}$ ), and breast and melanoma cancer tissues (data not shown) but did not react or reacted weakly with their normal counterparts (Figure 2, E and G). P9 also reacted with murine prostate cancer tissues (Figure 2D), indicating that P9 cross-reacted with murine Pim-1. In reactive cancer cells, the staining was mainly in the cytoplasm as well as nucleus (Figure 2, C, F, and H). The specific staining of $\mathrm{P} 9$ was also examined by Western blot analysis in various cancer cell lines. P9 deferentially reacted with 44- and $33-\mathrm{kDa}$ isoforms of PIM-1 as previously reported $(1,2,7,9)$ and also with a $37-\mathrm{kDa}$ PIM-1 (see Discussion) in prostate (PC3, DU145), breast (MCF7), colon (LS174T), lung (Ben), and leukemia cancer cell lines (CCRF/CEM, CEM/A7R) as well as murine prostate cancer cell line (TRAMP-C1), but it hardly reacted with leukemia cell line U937 (Figure 2I). The results further confirmed the specificity of P9 used in the immunohistochemical staining.

Binding of $m A b$ with cell surface PIM-1 analyzed by flow cytometry, cellular fraction, and transfection. The anti-PIM-1 mAbs were examined for both cell surface and intracellular binding to PIM-1 using flow cytometry analysis (Tables 1 and 2). P2, P3, P7, and P8 showed a high percentage (52\%-93.7\%) of intracellular staining in MCF7, Raji, K562, and NS1 cells. The noninhibitory mAbs, P3, P7, and P8, showed a higher percentage of intracellular binding than that of $\mathrm{P} 9$ in LOVO (P3, P7, P8, 65\%-84\% versus $\mathrm{P} 9,30 \%$; Table 1 ) or E3 cells (P3, P7, P8, 18\%-27\% versus P9, 14\%; Table 1). In contrast, cell surface staining of the anti-PIM-1 mAb tested by indirect immunofluorescence was much weaker than that tested by intracellular staining. Compared with the cell surface binding among the PIM-1 mAbs and the examined cell lines, a greater percentage (27.5\%) of P9 was observed in the K562 cells (Table 2). The results indicate that in addition to cytoplasmic and nuclear expression, PIM-1 is also expressed on the surface of some cancer cells. 


\section{Table 1}

Percentages of intracellular expression of PIM-1 in cancer cell lines

\begin{tabular}{lcccccc} 
mAbs & MCF7 & LOV0 & Raji & K562 & E3 & NS1 \\
P2 & 52.0 & 20.0 & 69.5 & 70.9 & 7.7 & 76.9 \\
P3 & 62.0 & 65.0 & 93.7 & 88.5 & 27.0 & 66.6 \\
P7 & 65.0 & 84.0 & 86.9 & 83.1 & 24.0 & 53.9 \\
P8 & 60.0 & 82.0 & NT & NT & 18.0 & NT \\
P9 & 66.0 & 30.0 & 90.8 & 91.9 & 14.0 & 91.3 \\
BC3 & 88.0 & 89.0 & 98.9 & 79.8 & 77.0 & 94.6 \\
PBS & 1.1 & 0.8 & 0.7 & 0.6 & 0.9 & 0.3 \\
\hline
\end{tabular}

Percentages were derived from flow cytometry testing of cancer cell lines using anti-PIM-1 mAbs. NT, not tested.

We believe this has not been previously reported, although PIM-1 activity was demonstrated in the cell membrane fraction or inner leaflet of the membrane $(7,9)$. To confirm the finding, we performed the following 5 experiments: (a) P9 was directly conjugated with FITC and used in flow cytometry. The FITC-conjugated P9 did not react with Raji (Figure 3A), weakly reacted with U937 (Figure 3B), and strongly reacted with K562, PC3, DU145, and LNCaP (Figure 3, C-F). In contrast, FITC-conjugated normal mouse IgM $(\mathrm{mIgM})$, as a negative control, did not react with any tested cancer cell line, and FITC-conjugated anti-MUC1 $\mathrm{mAb} B C 3$, as a positive control, strongly reacted with K562, PC3, DU145, and LNCaP cells as expected (Figure 3, C-F). (b) Immunofluorescence microscopy also showed linear or clustered cell surface staining by FITC-conjugated P9 in DU145 and TRAMP-C1 prostate cancer cells (Figure $3, \mathrm{G}$ and $\mathrm{H})$. The results clearly showed that PIM-1 indeed existed on the cancer cell surface. (c) Furthermore, the specific binding of P9 to cell surface PIM-1 was confirmed by biotinylation of cell surface protein. The PC3 cells were labeled with Sulfo-NHS-LCBiotin, lysed, and precleared by BC3, then immunoprecipitated by $\mathrm{P} 9$ and resolved in Western blot. Indeed, the 44-, 33-, and 37-kDa molecules were detected by streptavidin-HRP in the immunoprecipitate of P9 (Figure 3I, lane 1). The blot was also probed by P9 and detected by anti-mouse Ig-HRP (Figure 3I, lane 2), and the bands with similar molecular weights were also visualized. (d) To confirm the localization of PIM-1 on the cell membrane, subcellular fractions of DU145 cells were prepared and examined by P9 and rabbit anti-PIM-1 Abs (Figure 3J). The purity of each fraction was examined using cellular marker Abs such as anti-EGFR (as a cell membrane marker), anti-lamin A (as a nuclear marker), and anti-actin (as a cytosol marker) as shown in Figure 3J (blots iii-v). Rabbit anti-PIM-1 Ab reacted with 33- and 44-kDa of PIM-1 in the cell membrane and all other subcellular fractions (Figure 3J, blot i, lanes 1-4). Similar reactions were also observed with P9 in the same striped blot membrane (Figure 3J, blot ii, lanes 1-4). The results demonstrated that, apart from cytosol and nuclear fractions, PIM-1 is localized in the cell membrane and is specifically recognized by anti-PIM-1 mAb P9. (e) To further define the cell surface localization of the Pim-1 protein, a FLAG-tagged PIM-1 protein was expressed in CHOP cells, which have been used in the transient transfection for efficient expression of cell surface molecules (44). The specificity of mAb P9 binding to PIM-1 located on the cell surface was examined by immunofluorescence microscope (Figure 3, K-N) and flow cytometry (Figure 3, O and P). A linear fluorescence staining with anti-FLAG $\mathrm{mAb} M 2$ was shown on the cell surface of CHOP cells transfected with pBK-PIM-FLAG (Figure $3 \mathrm{~K})$ but not on the surface of CHOP cells transfected with $\mathrm{pBK}$ CMV vector (Figure $3 \mathrm{~L}$ ). Similar cell surface fluorescence staining of PIM-1 by anti-PIM-1 mAb P9 was also observed in CHOP cells transfected by pBK-CMV-PIM-1-FLAG (Figure 3M) but not by vector only (Figure $3 \mathrm{~N}$ ). Flow cytometric analysis of cell surface binding of PIM-1 demonstrated that $\mathrm{M} 2$ and $\mathrm{P} 9$ reacted with $\mathrm{pBK}$ CMV-PIM-1-FLAG transfected CHOP cells but not with pBK-CMV transfected CHOP cells (Figure 3, $\mathrm{O}$ and $\mathrm{P}$ ). When mouse IgM was used in flow cytometry as a control $\mathrm{Ab}$, no reaction was observed (Figure 3, $\mathrm{O}$ and $\mathrm{P}$ ). The results further confirmed the specific binding of P9 with cell surface expressed PIM-1. Thus, the data demonstrate that PIM-1 is indeed located in the outer leaflet of the plasma membrane and accessible by $\mathrm{mAb}$. The results extend Xie et al.'s finding of plasma membrane localization of PIM-1 (9).

Anti-PIM-1 mAb synergistically inbibited growth of drug resistant cells. The membrane location of PIM-1 has been reported to confer prostate cancer cell drug resistance as a result of direct interaction with tyrosine kinase Etk on the plasma membrane (9). The 44-kDa PIM-1 competes with tumor suppressor p53 for binding to Etk, activates Etk kinase activity or phosphorylates BCRP/ABCG2 (42), and protects human prostate cancer cells from apoptosis induced by chemotherapeutic drugs $(9,42)$. Knockdown PIM-1, using PIM1 siRNA, inhibited PIM-1 expression and sensitized the cancer cells to chemotherapeutic drugs doxorubicin or mitoxantrone (9). Cisplatin and epirubicin are important chemotherapy drugs used in the treatment of patients with hormone-resistant prostate cancer $(45,46)$. Apoptosis in cancer cells is recognized as a critical process that contributes to their drug sensitivity and drug resistance (47), a major obstacle in the management of prostate cancer. It was of interest to determine whether such binding of PIM-1 with Etk could be interrupted by P9 binding to PIM-1 and restore the drug sensitivity. Two-way ANOVA is frequently used to statistically determine whether 2 agents act synergistically when eliciting a biological response $(48,49)$. By using this analysis, we have previously demonstrated the synergistic effect of 2 different drugs or a combination of $\mathrm{mAb}$ and drugs in overcoming drug resistance $(50,51)$. In this study, we used the same strategy to examine the impact of combining anti-PIM-1 mAb and drugs on inhibition of DU145 cancer cell growth (Figure 4). As shown in Figure 4A, the interaction among various combinations of $\mathrm{P} 9$ and cisplatin was examined and analyzed statistically by 2 -way ANOVA on the results of inhibition of $\left[{ }^{3} \mathrm{H}\right]$-thymidine incorporation of DU145 cells. There was a statistically significant synergistic interaction

\section{Table 2}

Percentages of cell surface expression of PIM-1 in cancer cell lines

\begin{tabular}{lcccccc}
\hline mAbs & MCF7 & LOVO & Raji & K562 & E3 & NS1 \\
P2 & 3.7 & 1.7 & 2.4 & 4.6 & 1.1 & 4.0 \\
P3 & 9.8 & 3.1 & 3.9 & 21.0 & 4.0 & 7.9 \\
P7 & 12.2 & 3.9 & 7.5 & 24.8 & 9.1 & 14.6 \\
P8 & 10.0 & 2.7 & NT & NT & 7.1 & NT \\
P9 & 7.1 & 4.2 & 8.5 & 27.5 & 10.7 & 17.6 \\
BC3 & 96.6 & 4.9 & 0.7 & 8.2 & 2.2 & NT \\
PBS & 0.5 & 0.1 & 0.3 & 0.54 & 0.2 & 0.3 \\
\hline
\end{tabular}

Percentages were derived from flow cytometry testing of cancer cell lines using anti-PIM-1 mAbs. 


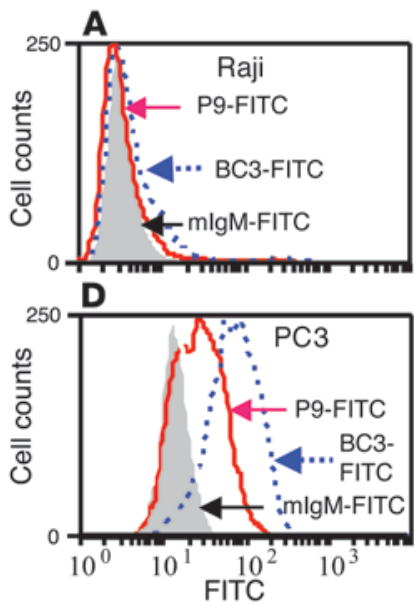

B

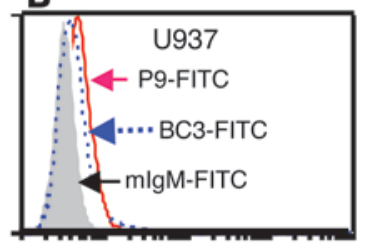

E

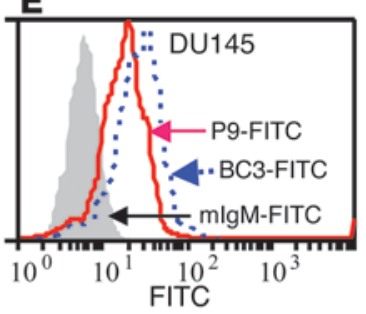

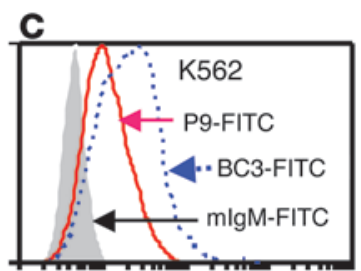

$\mathbf{F}$

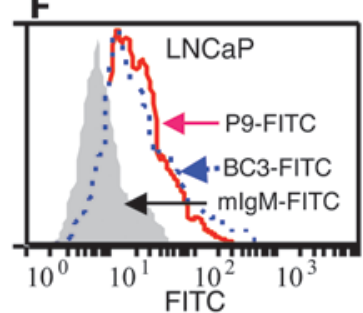

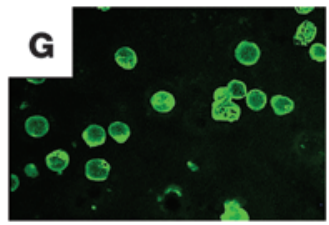
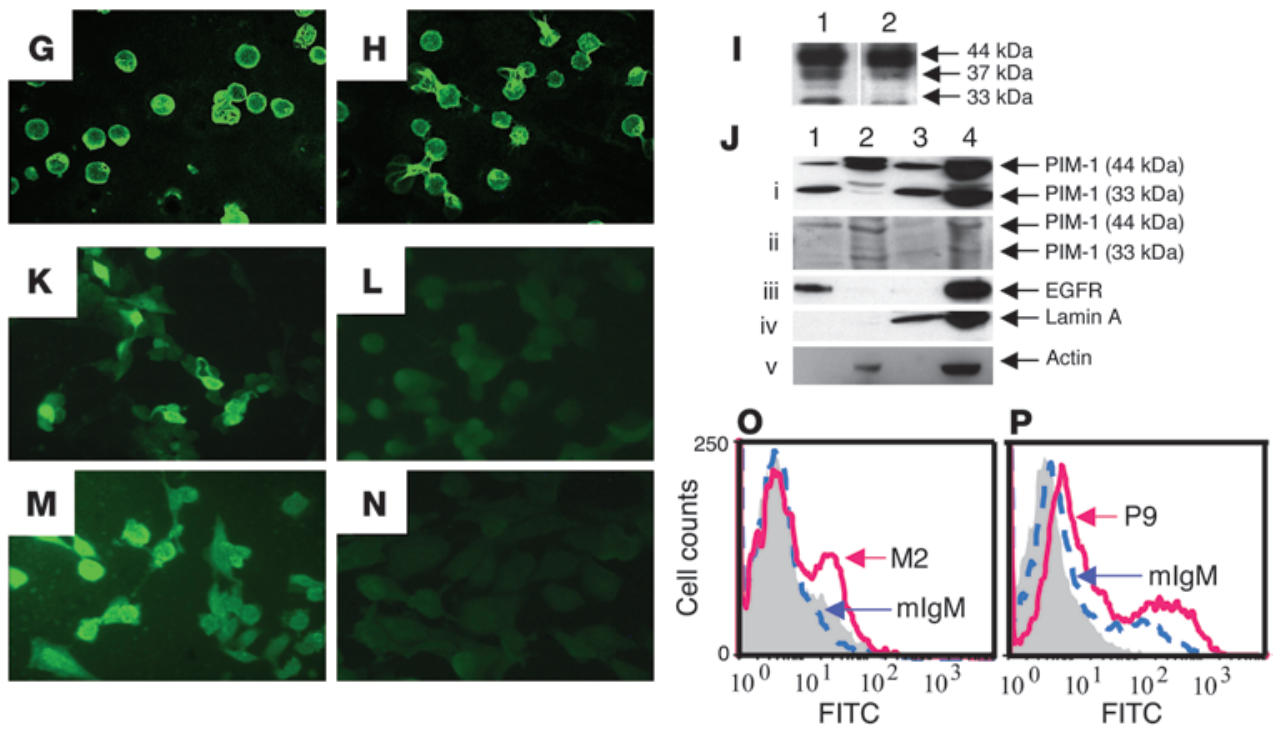

Figure 3

Detection of cell surface PIM-1 by P9. (A-F) The flow cytometry analysis of cancer cells shows binding of FITC-conjugated P9 (P9-FITC), FITCconjugated BC3 (BC3-FITC), and FITC-conjugated mlgM (mlgM-FITC) with cells from the following cancer cell lines: Raji (A), U937 (B), K562 (C), PC3 (D), DU145 (E), and LNCaP (F). (G and H) Immunofluorescence staining of FITC-conjugated P9 with DU145 (G) and TRAMP-C1 (H) shows linear or clustered cell surface staining of cancer cells. Original magnification, $\times 400$. (I) Immunoblots of biotinylated cell surface PIM-1 immunoprecipitated by P9 and detected by streptavidin-HRP (lane 1) and by P9/anti-mouse Ig-HRP (lane 2) in PC3 cancer cells. (J) Western blot analysis of cell membrane (lane 1), cytosol (lane 2), nuclear cellular fraction (lane 3), and total lysate (lane 4) prepared from DU145 cells, using a cellular fraction kit, and run on 10\% SDS-PAGE, immunoblotted, and detected by rabbit anti-PIM-1 (i), P9 (ii), anti-EGFR (iii), anti-lamin A (iv), and anti-actin (v) Abs. (K-N) Immunofluorescence of CHOP cells transfected with pBK-CMV-PIM-1-FLAG in chamber slides for 48 hours shows linear staining in the cell surface detected by anti-Flag M2 Ab (K) and P9 (M), respectively, but not in the cells transfected with pBK-CMV vector $(\mathbf{L}$ and $\mathbf{N})$. Original magnification, $\times 400$. ( $\mathbf{O}$ and $\mathbf{P})$ The flow cytometry analysis of CHOP cells transfected with $\mathrm{pBK}-\mathrm{CMV}$ vector or $\mathrm{pBK}-\mathrm{CMV}$ PIM-1-FLAG for 48 hours shows M2 $(\mathbf{O})$ and P9 $(\mathbf{P})$ reacted with CHOP cells transfected by pBK-CMV-PIM-1-FLAG (red line) but not reacted with $\mathrm{CHOP}$ cells transfected by pBK-CMV vector only (shadowed). Normal mouse IgM was used as negative control (dotted blue line).

$(P<0.05, P<0.001)$ with the combination of $\mathrm{P} 9$ and cisplatin (Figure $4 \mathrm{~A}$ ), in particular at around $\mathrm{IC}_{50}$, i.e., at the ranges of $2.5-5 \mu \mathrm{g} /$ $\mathrm{ml}$ of $\mathrm{P} 9$ and $0.0938-0.1875 \mu \mathrm{g} / \mathrm{ml}$ of cisplatin. For example, there was $72.3 \%$ and $49.7 \%$ of inhibition, respectively, when $5 \mu \mathrm{g} / \mathrm{ml}$ P9 and $0.0938 \mu \mathrm{g} / \mathrm{ml}$ cisplatin were used alone. In contrast, the inhibitory effect was synergistically increased to $81.3 \%$ when they were used together at the same concentrations (Figure 4A, $P<0.001$ ). The inhibitory effects of combinations of P9 and epirubicin (Figure 4B), P4 and cisplatin (Figure 4C), and P4 and epirubicin (Figure 4D) were examined on DU145 cells at lower concentration of each
$\mathrm{mAb}(\leq 3.1 \mu \mathrm{g} / \mathrm{ml})$. Similar synergistic effects were also obtained in combinations of P9 with epirubicin (Figure 4B, $P<0.01$ and $P<0.001$ ), P4 with cisplatin (Figure 4C, $P<0.001$ ), and P4 with epirubicin (Figure 4D, $P<0.05$ and $P<0.001$ ).

Apoptosis induced by anti-PIM-1 $m A b$. PIM-1 positive human leukemia CEM/A7R, a multidrug resistant cell line (52), was chosen in the study, as it was a good target to examine mAb-induced apoptosis (51). The CEM/A7R cells were incubated with $15 \mu \mathrm{g} / \mathrm{ml}$ of $\mathrm{P} 4$ or P9 for 24,48 , or 72 hours, and the surviving cells were counted using trypan blue dye exclusion assay. As shown in Fig- 

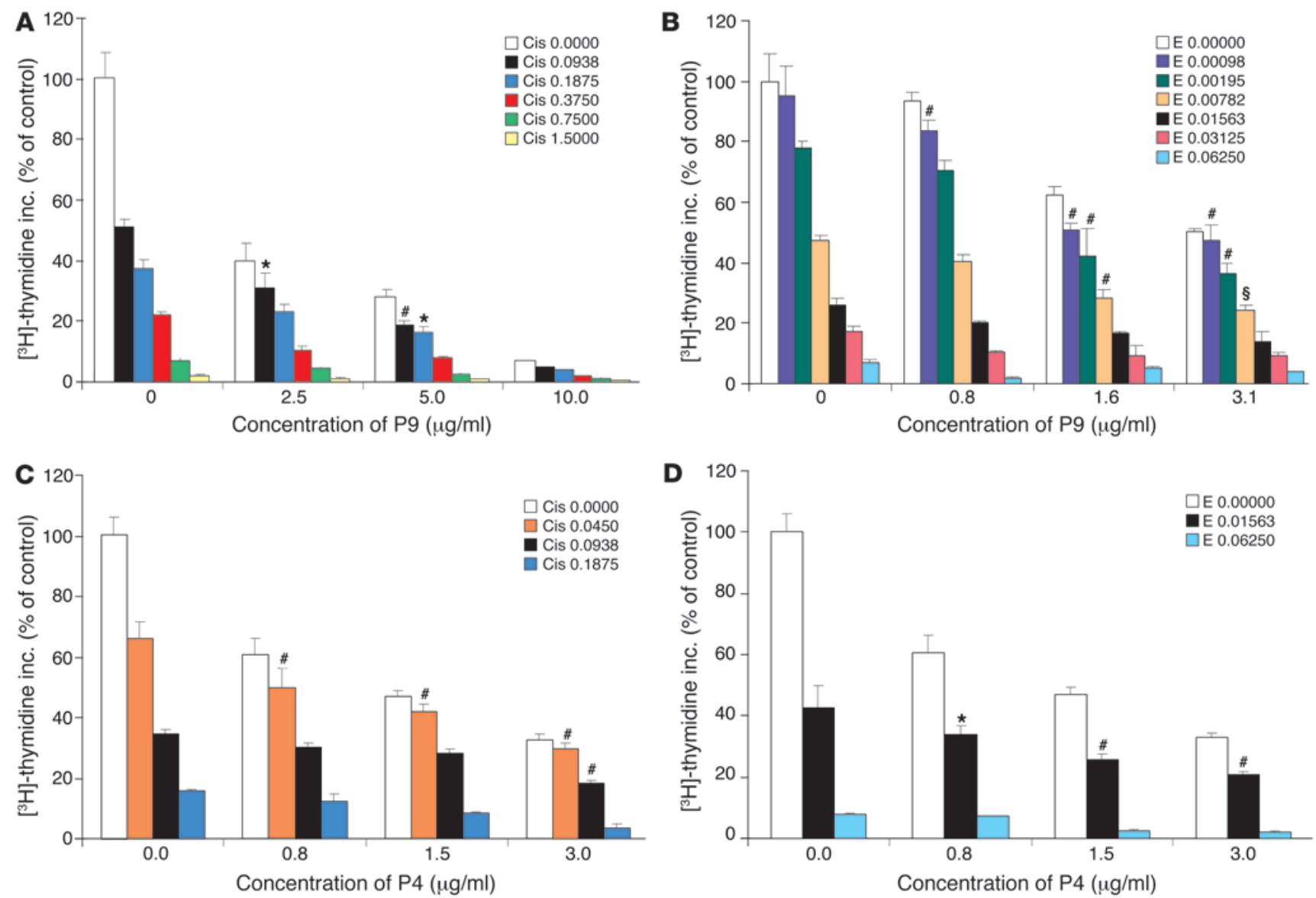

Figure 4

Combination effects of mAb and drugs on inhibition of cancer cell growth. Inhibition of DU145 cancer cell growth by combined use of (A) P9 and cisplatin (Cis), (B) P9 and epirubicin (E), (C) P4 and cisplatin, and (D) P4 and epirubicin for 48 hours of incubation as measured by percentage of control in $\left[{ }^{3} \mathrm{H}\right]$-thymidine incorporation assays is shown. Columns are means of triplicate experiments. Error bars represent $\pm \mathrm{SD}$ in triplicate experiments. The interactions of various concentrations of anti-PIM-1 mAb with cisplatin and epirubicin were subjected to 2-way ANOVA. There was a statistically significant synergistic interaction at the concentrations indicated with asterisks in the figure. ${ }^{\star} P<0.05 ; \$ P<0.01$; ${ }^{\sharp} P<0.001$.

ure $5 \mathrm{~A}, \mathrm{P} 4$ induced $20 \%, 77 \%$, and $70 \%$, while P9 induced $30 \%$, $77 \%$, and $90 \%$ of cell death, following 24,48 , and 72 hours of incubation, respectively, indicating that $\mathrm{mAb}$-induced cell death is time dependent. Induction of cell death by anti-PIM-1 mAb was also examined in monolayer cells. At $15 \mu \mathrm{g} / \mathrm{ml}, \mathrm{P} 4$ and P9 induced $48 \%-62 \%$ of cell death of DU145, PC3, and MCF7 cancer cells after 5 days culture (Figure 5B). Little cell death was observed in these cell lines in the presence of control $\mathrm{mAb} B C 3$ under the same culture condition (Figure 5, A and B). The early apoptotic cells induced by anti-Pim-1 mAb were examined by flow cytometry analysis of annexin $\mathrm{V}$ staining in CEM/A7R cells (53), following 4 hours of incubation with $25 \mu \mathrm{g} / \mathrm{ml}$ P9. P9 induced $6.8 \%$ of early apoptotic CEM/A7R cells compared with $1.2 \%$ of the cells cultured in medium (Figure 5, C and D). The later apoptotic cells stained by both annexin $\mathrm{V}$ and propidium iodide were $12.4 \%$ and $4.0 \%$ cultured in the presence of P9 and medium, respectively. Therefore, there were $19.2 \%(12.4 \%+6.8 \%)$ and $5.2 \%(4.0 \%+1.2 \%)$ of annexin $\mathrm{V}$-positive CEM/A7R cells in the presence or absence of P9, respectively (Figure 5, C and D), indicating an apoptotic pathway was being activated in cancer cells by specific interaction of P9 and PIM-1.
P9 treatment leads to disruption of the Hsp90/PIM-1 complex formation and reduced PIM-1 levels. Pim-1 is constitutively active; therefore, its protein levels correlate with kinase activity $(25,54)$. This means that control of PIM-1 levels must be necessary to inhibit tumorigenicity, cell survival, and proliferation. We previously demonstrated that Hsp90 protects PIM-1 from degradation by forming Hsp90/PIM-1 complexes (25). We postulate that P9 may function as a competitor that preferentially interrupts PIM- 1 complexing to Hsp90, which promotes stabilization of PIM-1. This would lead to decreased stability, resulting in decreased PIM-1 levels, and eventually lead to growth inhibition. To demonstrate whether this is the case, TRAMP-C1 cells were treated with $25 \mu \mathrm{g} / \mathrm{ml}$ P9 for 3 and 6 hours, lysed, coimmunoprecipitated, and Pim-1 and Hsp90 levels were evaluated by Western blot. In cells that were not treated with P9, Hsp90 was immunoprecipitated with Pim-1 by P9 mAb and Pim-1 was immunoprecipitated with Hsp90 by Hsp90 mAb (Figure 6A). Treatment of the cells with P9 mAb decreased the levels of Hsp90 proteins pulled down with Pim-1 in a time-dependent manner, detected by anti-Hsp90/anti-mouse HRP (Figure $6 \mathrm{~A}$, top panels). Furthermore, P9 treatment caused decrease of 44-, 37-, and 33-kDa Pim-1 in the anti-Hsp90 immunoprecipitated 

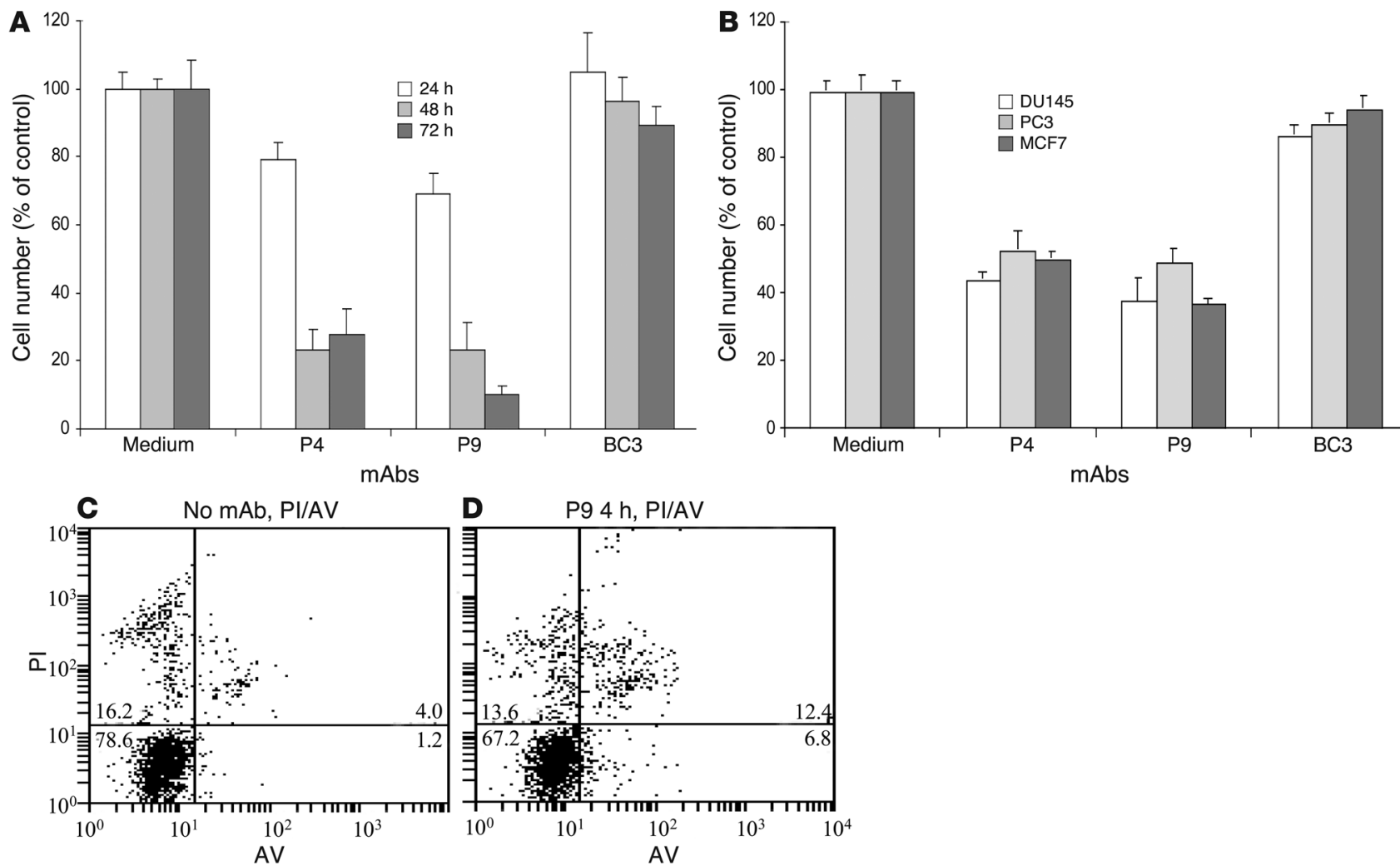

Figure 5

Detection of apoptosis induced by P9. (A) The percentage of CEM/A7R cells was calculated from the number of CEM/A7R cells cultured in the presence of $15 \mu \mathrm{g} / \mathrm{ml} \mathrm{P4}$ or P9 divided by the number of the cells cultured in the absence of P4 or P9 for 24, 48, and 72 hours, respectively. (B) The percentage DU145, PC3, and MCF7 cells was calculated from the numbers of DU145, PC3, and MCF7 cells cultured in the presence of $15 \mu \mathrm{g} / \mathrm{ml}$ P9 divided by the numbers of DU145, PC3 and MCF7 cells in the absence of P9 for 5 days, respectively. Columns show mean \pm SD of triplicate experiments as percentage compared with control. (C and D) Flow cytometry analysis of annexin $\mathrm{V}(\mathrm{AV})$ and propidium iodide (PI) dual staining of apoptotic CEM/A7R cells after 4 hours incubation with (C) medium or (D) $25 \mu \mathrm{g} / \mathrm{ml}$ of mAb P9. Numbers within the plots denote percentage of cells in each quadrant.

complexes, detected by P9/anti-mouse Ig-HRP (Figure 6A, middle left panel). In P9 immunoprecipitates, 44-kDa Pim-1 but not 33-kDa Pim-1 was decreased by P9 treatment, as detected by probing with P9/anti-mouse Ig-HRP (middle right panel, Figure 6A). This could be due to the less efficient binding of Protein L Gel to the $\kappa$ chain of mouse IgM to immunoprecipitate PIM- 1 compared with the Protein G-Agarose binding to the Fc of IgG to immunoprecipitate Hsp90. Indeed, further investigation using rabbit anti-Pim-1 Abs, which have multiple binding sites with higher affinity for Pim-1 than P9, revealed that P9 treatment caused a decrease of 44- as well as 33-kDa Pim-1 in the Pim-1/Hsp90 complexes, immunoprecipitated by either anti-Hsp90 or P9 (Figure $6 \mathrm{~A}$, bottom panels), indicating $\mathrm{P} 9$ interferes with the association of Pim-1 and Hsp90, leading to a decrease of their protein levels in a time-dependent fashion (Figure 6A). Furthermore, we also demonstrated that $\mathrm{P} 9$ reacted with 44-, 33-, and 37-kDa isoforms of PIM-1 in DU145 cell lysates. The levels of PIM-1 were slightly declined after 1 hour of treatment with P9, markedly reduced after 3 hours, and almost abolished after 6 hours of P9 treatment. Similar results were also demonstrated in PC 3 and TRAMP-C1 cells after 3 hours of treatment with P9 (Figure 6B). These results indicated that treatment of the cancer cell lines with $\mathrm{P} 9$ also decreased total levels of PIM-1 in a time-dependent manner.
Inbibition of Akt phosphorylation. Activation of the PI3K/Akt pathway is involved in regulation of PIM-1 expression under hormone stimulation (22) and prostate cancer progression $(55,56)$. However, Pim-1 overexpression increased Akt expression and phosphoAkt (Ser473) levels, indicating that there is a feedback mechanism between the 2 proteins (10). Because the phosphorylation state of Akt is modulated by binding to Hsp90 (57) and inhibition of Hsp90 downregulated Akt activity (58), an inhibition of Hsp90 induced by P9 could lead to an inhibition Akt activity. Therefore, it was expected that decreased PIM-1 levels induced by PIM-1 mAb might affect Akt and phospho-Akt (Ser473) levels (10). Western blot analysis of cell lysates from P9-treated DU145 cells demonstrated that the level of phosphorylation of Akt at Ser473 was decreased in a time-dependent manner, while the total Akt was unchanged (Figure 6C). A similar trend was also observed in PC3 and TRAMP-C1 cells treated with $25 \mu \mathrm{g} / \mathrm{ml}$ P9 for 3 hours (Figure $6 \mathrm{C}$ ). These results indicate that anti-PIM-1 mAb P9 somehow mediated the inhibition of the phosphorylation of Akt at Ser473, without affecting total levels of Akt, although the precise mechanism for this event remains to be elucidated.

Activation of the proapoptotic molecule Bad. PIM-1 phosphorylates Bad at Ser112 and also at Ser136 residues, which are also phosphorylated by Akt. Bad may be a nexus point, upon which 
A
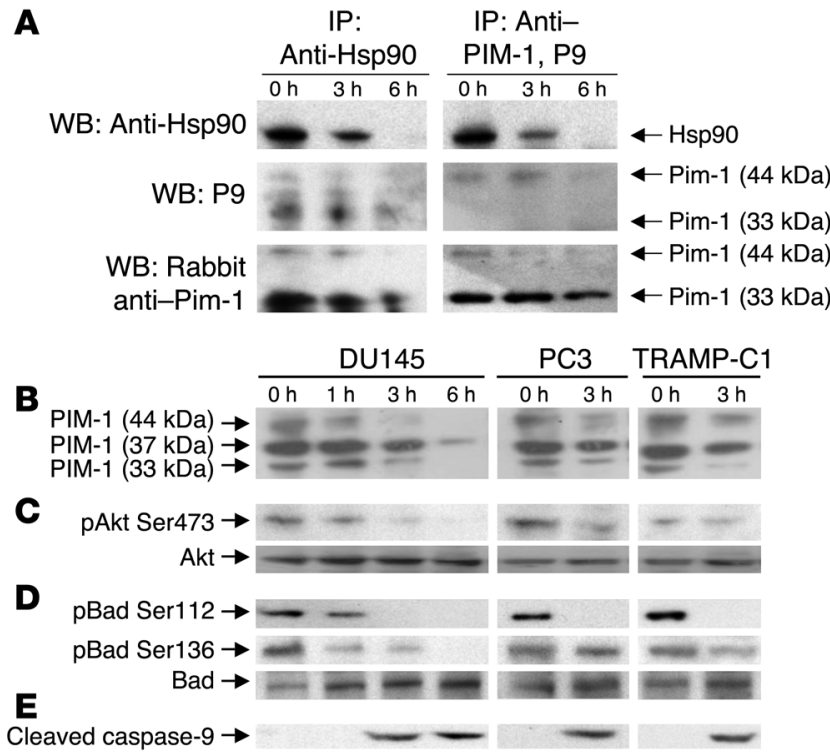

multiple signaling pathways converge in PIM-1-mediated cell survival and antiapoptotic activity. Since P9 leads to a decrease in PIM-1 levels and Akt phosphorylation, we next examined whether P9 treatment leads to less phosphorylation of Bad, thus promoting Bad proapoptotic activity. Indeed, P9 treatment resulted in less Bad phosphorylation at both Ser112 and Ser136 over time in DU145 cancer cells, without affecting total Bad protein (Figure 6D). Moreover, P9 also resulted in less phosphorylation of Bad at Ser112 but not at Ser136 in PC3 and TRAMP-C1 cancer cells (Figure 6D). These results are consistent with the decreased PIM-1 and Akt levels after P9 treatment, indicating that P9-induced apoptosis is mediated at least in part through the Bad apoptotic pathway.

Cleavage of caspase-9. Bad phosphorylation protects cells from apoptotic stimuli and attenuates death pathway signaling by raising the threshold at which mitochondria release cytochrome $\mathrm{c}$ to cytosol and activate caspase- 9 and caspase- 3 to induce cell death (38). Reduced phosphorylation of Bad mediated by P9 could lead to cytochrome $\mathrm{c}$ release from mitochondria and cleavage of caspase-9. We examined cleavage of caspase-9 in mAb P9-treated cells using Abs specifically reacting with a fragment of cleaved caspase- 9 at Asp330 and found that P9 treatment correlated with cleavage of caspase-9 at Asp330 in a time-dependent manner in DU145 cells. Similar results were also found with PC3 and TRAMP-C1 cells after 3 hours of treatment. The results indicate that activation of the mitochondria/caspase-9 apoptotic pathway is associated with P9-induced apoptosis (Figure 6E).

PIM-1 knockdown using PIM1 siRNA. To determine whether PIM-1 expression is directly involved in the pathway of PIM-1-mediated cell survival and the apoptotic response to anti-PIM-1 mAb P9, PIM-1-expressing prostate cancer cells were treated using HP Validated PIM1 siRNA for 72 hours. The flow cytometric analysis demonstrated that the mean value of FITC-conjugated P9 binding of cell surface expression of Pim-1 was declined from 41.0, 95.0, and 73.0 to 25.1, 59.0, and 31.0, respectively, in DU145, PC3, and TRAMP-C1 cells transfected with PIM1 siRNA compared with that of cells transfected with control siRNA (Figure 7, A-C), indicating that PIM-1 cell surface expression was substantially reduced. Trypan blue dye exclusion showed that transfection with PIM1 siRNA

\section{Figure 6}

Effect of mAb P9 on Hsp90 association with Pim-1 and changes on the levels and phosphorylation status of relevant proteins in DU145, PC3, and TRAMP-C1 cells, which were treated with $25 \mu \mathrm{g} / \mathrm{ml} \mathrm{P9}$ for the time indicated. (A) Western blots (WBs) of immunocomplexes precipitated by anti-Hsp90 mAb (left panel) or P9 (right panel) from P9-treated TRAMP-C1 cells, demonstrating decreased interaction between Pim-1 and $\mathrm{Hsp} 90$ proteins detected by anti-Hsp90/anti-mouse lg-HRP (upper row), P9/anti-mouse Ig-HRP (middle row), or rabbit anti-Pim-1 Abs/ anti-rabbit Ig-HRP (bottom row), respectively. (B-E) Western blot analyses (B) for PIM-1 expression, showing that the levels of PIM-1 were decreased after P9 treatment, and (C) for phospho-Akt, demonstrating that P9 treatment decreased levels of phospho-Akt at Ser473 without changing total Akt levels. (D) Western blot analyses showing decreased levels of phospho-Bad at Ser112 and Ser136 compared with total levels of Bad and (E) that P9 induced cleavage of caspase-9 at Asp330.

induced $42 \%, 43 \%$, and $39 \%$ of cell death in TRAMP-C1, PC 3 , and DU145 cells, respectively, compared with control siRNA (Figure 7D). These results are consistent with those reported recently (30). Furthermore, to confirm the findings described above (Figure 6, B-E), Western blot analysis of the DU145 cells following 66 and 78 hours of the PIM1 siRNA transfection demonstrated there was a reduction of Akt phosphorylation at Ser473 in a time-dependent manner. There was also little change in the total Akt level compared with the DU145 cells transfected with control siRNA, demonstrating that the PIM1 siRNA inhibited Akt phosphorylation at Ser473 (Figure 7E). This is consistent with the finding of a feedback signaling function between PIM-1 and Akt (10). Knockdown of PIM-1 expression also decreased Bad phosphorylation at Ser112 and Ser136 without changes in total Bad, while there was an increased level of cleaved caspase- 9 (Figure 7E). Thus, the results indicate that the inhibition of PIM-1 by siRNA is responsible for the inhibition of Akt phosphorylation and dephosphorylation of Bad and is consistent with the treatment by anti-PIM-1 mAb P9. The results indicate that it is the PIM-1 reduction, induced by either anti-PIM-1 mAb or PIM1 siRNA, which interrupted Akt and Bad signal pathways and eventually led to the cell apoptosis.

Antitumor effect of PIM-1 mAb in mice. The antitumor effect of PIM-1 mAb in vivo was examined using 2 mouse models (Figure 8). In a xenograft model, SCID mice were injected with $0.5 \mathrm{mg}$ P9 or P4 per mouse intraperitoneally after 8 hours of inoculation of DU145 human prostate cancer cells $\left(1 \times 10^{7}\right)$, followed by 6 injections of $0.25 \mathrm{mg}$ P9 or P4 (total of $2.0 \mathrm{mg}$ per mouse) as indicated in Figure 8A. Twenty-four days after tumor cell inoculation, the tumor size was significantly smaller in the P9- or P4-treated groups (mean 341 or $427 \mathrm{~mm}^{3}$ ) compared with the untreated control $\left(986 \mathrm{~mm}^{3}, n=5 ; P<0.05\right)$. These results showed the growth of the tumors to be reduced by $65.5 \%$ and $57.0 \% 7$ days after the last $\mathrm{mAb}$ treatment, demonstrating the inhibitory effects of antiPIM-1 mAb to be durable. In a syngenetic model of an established tumor graft, $\mathrm{C} 57 \mathrm{BL} / 6$ mice $\left(\mathrm{H} 2^{\mathrm{b}}\right)$, with murine prostate TRAMP$\mathrm{C} 1\left(\mathrm{H} 2^{\mathrm{b}}\right)$ tumors (mean size $50 \mathrm{~mm}^{3}$ ), were treated with $0.5 \mathrm{mg}$ P9, followed by another 9 injections of $0.25 \mathrm{mg}$ (total of $2.75 \mathrm{mg}$ ). The resulting tumor size was significantly smaller $(61.3 \%)$ in the 


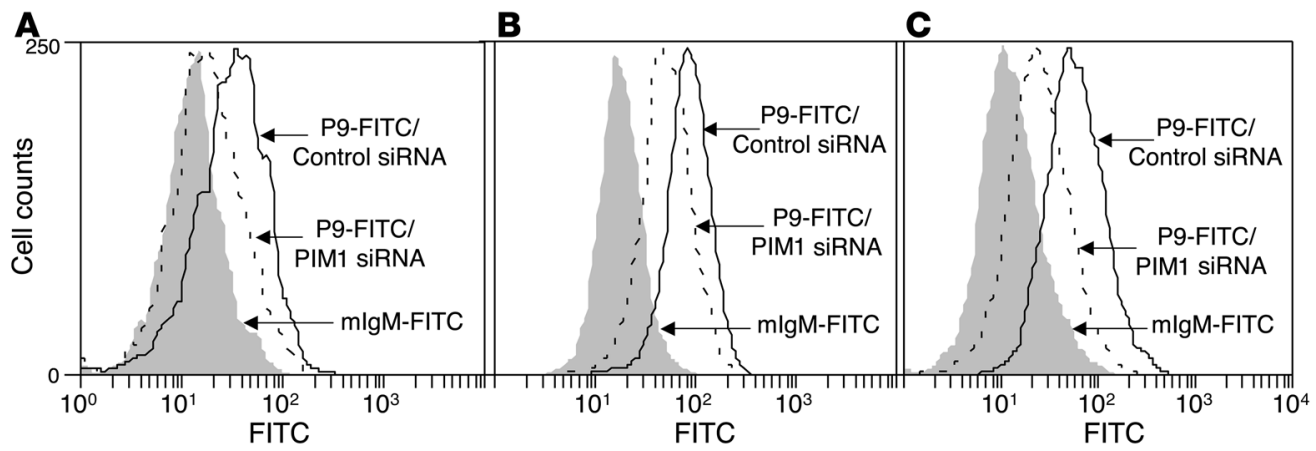

D

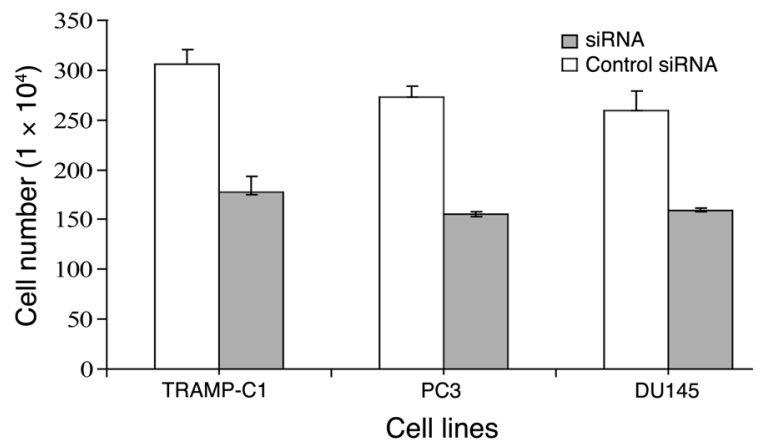

$\mathbf{E}$

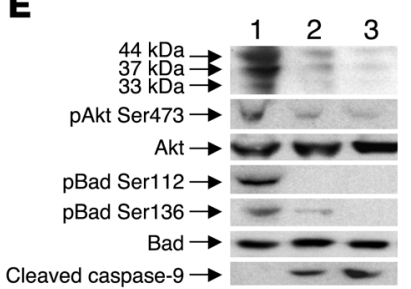

Figure 7

The effect of siRNA-mediated PIM1 knockdown on PIM-1 expression, cell growth, and phosphorylation of Akt and Bad. (A-C) Flow cytometry analysis shows reduced FITC-conjugated P9 binding to cell surface PIM-1 in DU145 (A), PC3 (B) and TRAMP-C1 (C) cells, respectively, after 72 hours of transfection with PIM1 siRNA (dotted line) and control siRNA (solid line). FITC-conjugated mlgM was used as negative control in the PIM1 siRNA transfected cells (gray area). (D) Trypan blue exclusion assay shows that transfection with PIM1 siRNA for 72 hours induced $42 \%$, $43 \%$, and $39 \%$ of cell death in TRAMP-C1, PC3, and DU145 cells, respectively, compared with the cells transfected with controls siRNA. Columns show means of viable cell counts of triplicate experiments; bars represent \pm SD. (E) Western blot analysis of the DU145 cells following PIM1 siRNA transfection shows decreased levels of 44-, 33-, and 37-kDa molecule of PIM-1; reduced phosphorylation of Akt at Ser473, without changing total Akt levels, and promoted dephosphorylation of Bad at Ser112 and Ser136 compared with total levels of Bad; and induced cleavage of caspase-9 at Asp33 following 66 hours (lane 2) and 78 hours (lane 3) transfection using PIM1 siRNA compared with control siRNA (lane 1).

P9-treated group (mean size $360 \mathrm{~mm}^{3}$ ) compared with the untreated control $\left(930 \mathrm{~mm}^{3}, n=5 ; P<0.05\right.$; Figure $\left.8 \mathrm{~B}\right)$. No obvious toxicity was observed in mice during $\mathrm{mAb}$ treatment. These results indicate that the anti-Pim-1 mAb suppressed cancer cell growth and may be of value in the treatment of prostate cancer.

\section{Discussion}

The compelling evidence of the involvement of the serine/threonine kinase PIM-1 in the development and progression of several different cancers has made it a potential pharmaceutical tumor target (43). There are a few small molecule inhibitors showing an inhibitory effect on PIM-1 (59). However, none have yet been reportedly used in animal and clinical application (43). In this study, we report for the first time that anti-PIM-1 mAb can function as an effective inhibitor of PIM-1, showing significant suppression of cancer cell growth in vitro and in animal models of human and murine prostate cancers. In addition, the mAb synergistically enhanced cytotoxicity of chemotherapeutic agents, epirubicin and cisplatin, demonstrating its ability to overcome PIM-1 conferred drug resistance. Our results suggest that mAbs targeting PIM-1, or a regimen involving a combination of PIM-1-specific $m A b s$ and chemotherapeutic drugs, may provide promising options for cancer treatment.

The specificity of $\mathrm{mAb}$ P9 to PIM-1 has been shown in previous studies $(25,34,35)$, in which P9 specifically immunoprecipitated
PIM-1 molecules from PIM1 gene transfectant cells. This immunoprecipitated PIM-1 was shown to bind to 19F7, a widely used PIM-1 mAb in many publications (9). In this paper, we further showed that the anti-PIM-1 mAb P9 specifically reacted with PIM-1, since it bound to recombinant GST-PIM-1 but not recombinant GST-Muc1. In contrast, the anti-Muc1 mAb M30 reacted with GST-Muc1, not with GST-PIM-1 (Figure 1A). Specific and strong reactions of anti-PIM-1 mAb P9 with prostate cancer cell lines were also demonstrated by flow cytometric analyses (Figure 3). Furthermore, P9 specifically stained PIM-1 protein in several cancer cell lines and tissues, including prostate, colon, breast, and lung (Figure 2). We noticed that P9 reacted with 44- and 33-kDa PIM-1 as well as a 37-kDa protein (Figure 2I, Figure 3I, and Figure $6 \mathrm{~B})$, and the similar 37-kDa molecule was also previously detected by mAb $19 \mathrm{~F} 7$ or polyclonal Ab to PIM-1 in cancer cell lines or PIM1 gene transfectant cell lines $(7,9)$. Because the intensity of this band varies somewhat from sample to sample, we suspect that it may be the result of either proteolytic cleavage or posttranslational modification of PIM-1 (9).

The serine/threonine kinase PIM-1 has been reported to be expressed mainly in cytosol and nucleus (7), although possible membrane location has been implicated $(7,9)$. In this paper, we reported for what we believe to be the first time that cell surface expression of PIM-1 was detected using anti-PIM-1 mAb P9 by flow cytometry, immunofluorescent microscopy, biotinylation 

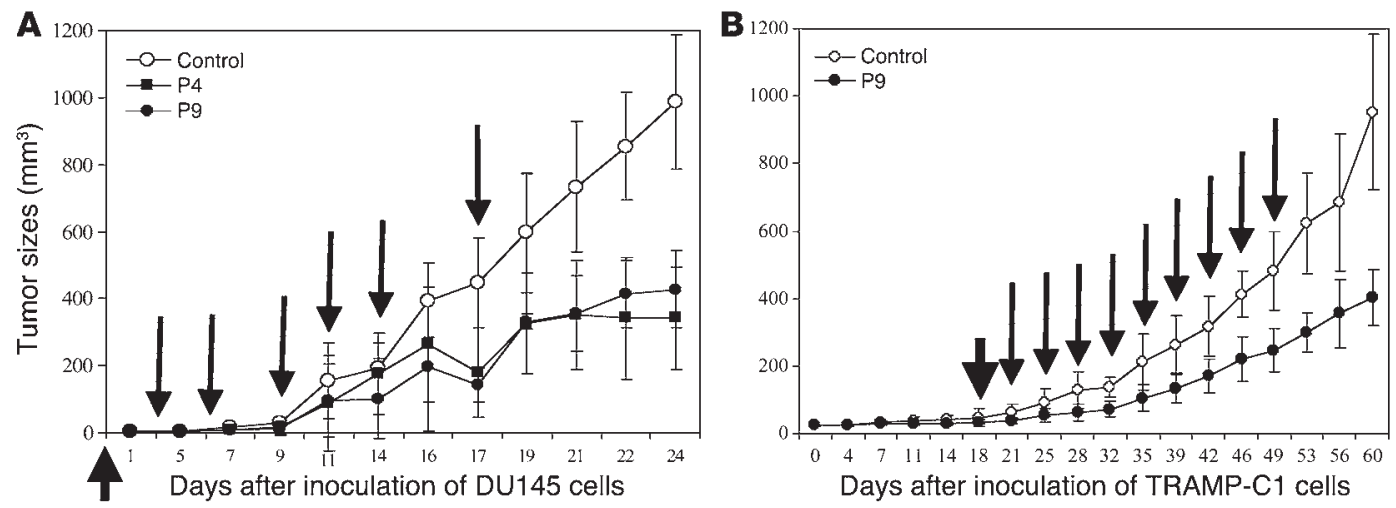

\section{Figure 8}

The tumor sizes in mice treated using anti-PIM-1 mAb. (A) SCID mice ( $n=5 /$ group) were inoculated with $1 \times 10^{7}$ of DU145 subcutaneously and treated with $0.5 \mathrm{mg}$ mAb P9, P4, or PBS per mouse after 8 hours of inoculation (thick arrow), followed by serial mAb injections of $0.25 \mathrm{mg}$ as indicated (arrows). (B) C57BL/6 mice ( $n=5 /$ group) were inoculated with $5 \times 10^{6}$ of TRAMP-C1 cells subcutaneously and treated with $0.5 \mathrm{mg}$ $\mathrm{mAb}$ P9 or PBS after tumor size reached a mean size of $50 \mathrm{~mm}^{3}$, followed by injections of $0.25 \mathrm{mg} \mathrm{mAb} \mathrm{P9}$ as indicated (arrows). Bars represent means of tumor size of 5 mice, and error bars represent \pm SD. Mean differences were compared by Mann-Whitney nonparametric $U$ test.

of cell surface protein, and cell fraction as well as expression of a FLAG-tagged PIM- 1 in CHOP cells (Tables 1 and 2 and Figure 3 ). In particular, the bindings of P9 to PIM-1 are substantially decreased when PIM1 siRNA knocked down PIM-1 expression in these cancer cells (Figure 7), providing strong evidence that specific cell surface binding of mAb P9 is indeed to PIM-1. This is a very important finding as it may explain how mAb P9 binds to PIM-1, which is located in the cytosol or nucleus, and could also be translocated to the outer leaflet of cell membrane. In fact, there are a number of signaling molecules known as cytosolic proteins, such as GTPases, Src and PI3K, which are also found localized to plasma membrane through recruitment of the molecules to lipid rafts (60) by protein electrostatics or FERM domain $(61,62)$. In view of PIM-1, the existence of 3 myristoylation sites at N-terminal end, as predicted by the Prosite program (63), would probably promote PIM-1 translocation to the cell surface. In addition, PIM-1 localization on the cell surface could be a result of direct interaction of the PIM-1 PXXP motif with a SH3 domain containing proteins situated on the plasma membrane or interaction with other membrane-associated signaling molecules $(9,64)$. It is possible that PIM-1 physically associates with some proteins such as Bad (65), which are located in lipid rafts, and as a result may promote PIM-1 cellular relocalization (66). In response to intra- or extracellular stimuli, lipid rafts can include or exclude proteins such as Bad to a variable extent that favors specific protein-protein interactions and modulates the activity of signaling cascades $(65,66)$.

The crystal structure of PIM-1 reveals an active conformation and demonstrates that PIM-1 is a constitutively active kinase. This emphasizes the prominent role that an increased level of PIM-1 protein has involved in tumor development and progression (54). It is reported that PIM-1 protein normally has a short half-life of 5 to 10 minutes in primary cells $(7,67)$. In contrast, the half-life of PIM-1 is at least 100 minutes in tumor cells (25). These findings indicate that an increase in half-life, rather than just an increase in transcription rate, may be a major factor in the increased levels of PIM-1 in tumor cells. The maintenance and degradation of PIM-1 protein is affected by heat shock proteins Hsp90 through binding to PIM-1. Once such physical association of PIM-1 and Hsp90 was blocked and disrupted by the Hsp90-specific inhibitor geldanamycin $(24,25,68)$, the half-life of PIM-1 was shortened and the level of PIM-1 protein was decreased $(24,25)$. In our study, we demonstrated that Hsp90 was immunoprecipitated with Pim-1 by mAb P9 in TRAMP-C1 cells lacking treatment with P9, and the specific binding of P9 to Pim-1 in immunocomplex of Pim-1/Hsp90 was decreased in P9-treated TRAMP-C1 cells (Figure 6A). The results indicate that $\mathrm{mAb}$ P9 functions as a Hsp90 competitor in interrupting an interaction between Pim-1 and Hsp90. This in turn would lead to PIM-1 destabilization and degradation and, therefore, decreased levels of PIM-1 (25). Indeed, we showed that mAb P9 treatment dramatically decreased PIM-1 protein in DU145, PC-3, and TRAMP-C1 prostate cancer cells in a time-dependent manner and totally suppressed PIM- 1 after 6 hours (Figure 6B). The results demonstrated that $\mathrm{mAb} P 9$ acted as an effective inhibitor of the PIM-1 kinase (Figure 6B) in inhibition of tumor growth (Figure 8). Therefore, inhibition of PIM-1 expression may be an attractive anticancer strategy and could be achieved by using anti-PIM-1 $\mathrm{mAb}$ as we showed in this study. Meanwhile, interruption of the interaction between Hsp90 and PIM-1 by P9 treatment not only affected PIM-1 expression (Figure 6, A and B) but also inhibited Hsp90 expression, revealing a feedback relationship between Pim-1 and Hsp90 (Figure 6A). The findings are important as Hsp90 inhibition is a goal for the development of cancer therapeutics (69). Because PIM-1 directly interacts with and phosphorylates c-Myc protein, leading to an increase in its stability (70), which in turn directly activates $H s p 90$ transcription (71), it is possible that anti-PIM-1 mAb P9 might regulate Hsp90 expression through an intervention of PIM-1-mediated activation of the c-Myc signaling pathway $(31,70,71)$. Whether P9 causes inhibition of c-Myc-regulated induction of Hsp90 transcription will be further studied.

PIM-1 and Akt appear to play redundant roles in regulating cellular proliferation and survival, possibly due to similar substrate specificities shared by PIM-1 and Akt, such as Bad (28). PIM-1 is independent of the Akt pathway in nontransformed hematopoietic cells (72) but acts downstream of Akt with feedback signaling connections in cardiomyocytes (10). Akt kinase activity is dependent on being phosphorylated on specific residues, which 
are modulated by binding to Hsp90 (57), and results in Hsp90 inhibition of Akt activity (58). Phosphorylation changes in Akt caused by mAb P9 could be due to P9-induced Hsp90 inhibition as shown in Figure 6A. Furthermore, special attention has been recently paid to specific Abs disturbing the hinge-bending movement of the kinase in modulating signaling pathways, including the PI3K/Akt pathway (73). Akt is recruited from the cytosol to the plasma membrane, in which it was phosphorylated at Thr308 and Ser473 by PDK1 in a PI3K-dependent manner (74). PIM-1 kinase is constitutively active as its native structure is in an active conformation with a novel hinge region (54). This structure resembles PI3K more closely than it does other protein kinases, although there is little sequence homology between PIM-1 and PI3K (75). Whether specific $\mathrm{mAb}$ to PIM-1 could induce conformational changes of the hinge region by using the unique active site of the PIM-1 and inhibit PI3/Akt kinase activity $(54,73,75)$ is the subject for the future studies. Upregulation of the PI3K/Akt pathway is linked to prostate cancer progression $(55,56)$. Akt couples survival signals to the cell death machinery through phosphorylation of Bad at Ser136 (76) and PIM-1 reverses Bad-induced cell death by phosphorylating it on multiple sites, including the Ser112 gatekeeper site (40) as well as Ser136 and Ser155 (41). Because PIM-1 is constitutively active, the decreased levels of Pim-1 must be contributing to the induction of apoptosis, which correlates with the decrease in phosphorylation of Bad Ser112 and Ser136 mediated by the mAb P9 as shown in Figures 6 and 7. Without doubt, decreased kinase activity of Akt induced by PIM-1 mAb would also be a contributing factor in a decrease in phosphorylation of Bad at Ser136 in PIM-1 mAb-induced cell death.

In summary, we have demonstrated that PIM- 1 mAb treatment of cancer cells leads to decreased PIM-1 levels, Akt phosphorylation at Ser473, and Bad phosphorylation at Ser136 and Ser112, which leads in turn to the activation of the mitochondrial apoptotic pathway, as indicated by induction of cleavage of caspase- 9 and suppression of tumor growth. These findings are important because they provide the first evidence that we know of that an effective treatment of certain cancers, such as prostate, may be possible by targeting PIM-1 kinase using mAb-based therapy.

\section{Methods}

Production and characterization of anti-PIM-1 mAb. Recombinant GSTPIM-1 was produced from a bacteria expression system and purified by Glutathione-Agarose (Sigma-Aldrich) (77). Murine myeloma NS1 cells were fused with spleen cells from BALB/c mice that were immunized with GST-PIM-1 three times (78). The first immunization was injected intraperitoneally with $100 \mu \mathrm{g}$ GST-PIM-1 emulsified in complete Freund's adjuvant. After 4 weeks, a second injection of $100 \mu \mathrm{g}$ GST-PIM-1 in PBS was given. Two weeks later, a third injection followed. Hybridomas were screened by ELISA and immunohistochemistry for their activity and specificity. The positive clones (P1-P10) were further selected by cell growth assays. The mAbs P4 and P9, which showed tumor inhibition, were purified from ascites by Sephacryl S300 HR gel filtration (Amersham Pharmacia Biotech) after $50 \%$ saturated ammonium sulfate precipitation. The subclasses of the mAbs P4 and P9 were determined using anti-mouse immunoglobulin subclass Abs (Serotec) by Ouchterlony test. Anti-human MUC1 mAb BC3 (IgM subclass) and mIgM were purified and used as isotype matched controls.

Cell lines and cytotoxic drugs. Human cancer cell lines used in the study were DU145, PC3, and LNCaP (prostate); LS174T and LOVO (colon); MCF7 (breast); BEN (lung); K562 (erythroleukemia); Raji (Burkitt's lym- phoma); U937 (myeloid leukemia); CCRF/CEM (leukemia); and CEM/ A7R (a drug-resistant leukemia) (52). Murine cancer cell lines TRAMP-C1 (prostate), NS1 (myeloma), and E3 (thymoma) were also used. The human and murine cells were cultured in RPMI 1640 or DMEM medium, containing $10 \%$ heat-inactivated $\mathrm{FCS}$ at $37^{\circ} \mathrm{C}$ in a $5 \% \mathrm{CO}_{2}$ humidified incubator, respectively. Cytotoxic drugs cisplatin and epirubicin (Pharmacia \& Upjohn Pty Limited) were used in combination with anti-PIM-1 mAb in the cell growth assays.

ELISA. GST-PIM-1 and GST-Muc1 (murine recombinant mucin 1) were coated at $5 \mu \mathrm{g} / \mathrm{ml}$ in carbonate buffer ( $\mathrm{pH}$ 9.6) onto the wells of a 96-well polyvinyl chloride plate (Costar) overnight at $4{ }^{\circ} \mathrm{C}$ and blocked with $1 \%$ BSA for 1 hour at $37^{\circ} \mathrm{C}$. Supernatants containing mAbs from tissue culture of hybridomas were added to the wells. The binding of Abs to the antigens was detected by sheep anti-mouse immunoglobulin labeled with HRP (Chemicon). The OD value was measured at $405 \mathrm{~nm}$, after adding substrate $0.03 \%$ 2, 2-azino-di-3-ethylbenzthiazoline sulfonate/ $0.02 \% \mathrm{H}_{2} \mathrm{O}_{2}$ by ELISA reader (78).

Cell proliferation assays. $\left[{ }^{3} \mathrm{H}\right]$-thymidine incorporation assay was performed as previously described (50). Briefly, $5 \times 10^{3}$ cancer cells per well were cultured for 48 hours at $37^{\circ} \mathrm{C}$ in $5 \% \mathrm{CO}_{2}$, with various concentrations of anti-PIM-1 mAb or chemotherapeutic agents cisplatin or epirubicin. The cells were pulsed with $\left[{ }^{3} \mathrm{H}\right]$-thymidine $(1 \mu \mathrm{ci} / \mathrm{ml})$ for 4 hours and then harvested onto glass filter papers using an automated cell harvester. The radioactivity of cell-incorporated $\left[{ }^{3} \mathrm{H}\right]$-thymidine was measured by TopCount (PerkinElmer). All assays were performed in triplicate, and the results were expressed as percentage of $\left[{ }^{3} \mathrm{H}\right]$-thymidine incorporation in the treated group compared with control (medium only) (78).

Immunoperoxidase staining. Human tissues were obtained from the Department of Anatomical Pathology, Austin Health, Heidelberg, Australia. Cancer cells from tissue culture were harvested and suspended in PBS, dispensed onto the slides, quickly dried, and fixed using ice-cold acetone. The cancer cells and formalin-fixed tumor tissue sections were stained with the anti-PIM-1 mAb and anti-mouse immunoglobulins linked to HRP (Chemicon) (78).

Conjugation of the mAb with FITC. To demonstrate mAb binds to PIM-1 on the cell surface, FITC (Sigma-Aldrich) was conjugated to anti-PIM-1 $\mathrm{mAb} \mathrm{P} 9, \mathrm{BC} 3$, and $\mathrm{mIgM}$, respectively, using the standard method. Briefly, mAbs were dialyzed in FITC-labeling buffer for 48 hours at $4^{\circ} \mathrm{C}$ and then incubated with freshly prepared FITC/DMSO $(5 \mathrm{mg} / \mathrm{ml})$ at ratio of $15 \mu \mathrm{l}$ of FITC/DMSO per milligram of $\mathrm{mAb}$ at room temperature for 2 hours. The unbound FITC was removed by using a PD 10 column (Amersham Pharmacia Biotec AB).

Immunofluorescence microscopy. Cells $\left(1 \times 10^{6}\right)$ were incubated with FITClabeled anti-PIM-1 mAb P9 and isotype matched FITC-conjugated BC3 and FITC-conjugated $\mathrm{mIgM}$ at $10 \mu \mathrm{g} / \mathrm{ml}$ for 30 minutes at $4^{\circ} \mathrm{C}$. The cells were applied to the slides and examined by immunofluorescence microscope, following washing with PBS 3 times.

Flow cytometry analysis of $m A b$ binding to PIM-1 on cancer cells. For direct detection of $\mathrm{mAb}$ binding to PIM-1, cells $\left(5 \times 10^{5}\right)$ were incubated with FITC-conjugated P9, FITC-conjugated BC3, and FITC-conjugated mIgM at $10 \mu \mathrm{g} / \mathrm{ml}$ for 30 minutes at $4^{\circ} \mathrm{C}$, respectively. The cells were washed and resuspended in PBS and examined with a FACScan Flow Cytometer (Becton Dickinson). For indirect detection of mAb binding to PIM-1, FITCconjugated sheep anti-mouse immunoglobulin (Chemicon) at 1:80 dilution was added to the cells following 3 washes with PBS, containing $2 \%$ newborn calf serum, after the cells were incubated with anti-PIM- $1 \mathrm{mAb}$, $\mathrm{mIgM}$, or $\mathrm{BC} 3$ for 30 minutes at $4^{\circ} \mathrm{C}$. The cells were subjected to a FACScan Flow Cytometer (78). To test intracellular expression of PIM-1, the cancer cells were fixed with $3.7 \%$ paraformaldehyde for 10 minutes and washed using saponin mixture, containing $0.2 \%$ saponin, $1 \%$ newborn calf serum, and $0.02 \%$ azide in PBS. Nonspecific binding/autofluorescence of 
the cells was blocked in $100 \mu \mathrm{l}$ of neat FCS for 20 minutes. P9 or control $\mathrm{mAb}$ was added, and the reaction of $\mathrm{P} 9$ was detected by adding anti-mouse Ig-FITC and analyzed by FACScan Flow Cytometer.

Trypan blue dye exclusion assay. To measure viable cell numbers following treatment with anti-PIM-1 mAb, cancer cells DU145, PC3, and MCF7 were seeded in $25-\mathrm{cm}^{2}$ flasks at a concentration of $5 \times 10^{4}$ cells in $10 \mathrm{ml}$ of medium and incubated overnight, respectively. Anti-PIM-1 mAb P9 $(25 \mu \mathrm{g} / \mathrm{ml})$ was added to the culture. Five days later, viable cells were counted by trypan blue exclusion (78). The human leukemia cells CEM/A7 $\left(2 \times 10^{5}\right)$ were incubated with P9 at $15 \mu \mathrm{g} / \mathrm{ml}$ for 24,48 , and 72 hours, respectively, and the cell numbers were counted using same method.

Annexin $V$ binding assay. Annexin $\mathrm{V}$ and propidium iodide dual staining were used to detect early apoptotic cells (53) induced by anti-PIM-1 mAb. The cancer cells $\left(2 \times 10^{5}\right)$ were incubated with or without $25 \mu \mathrm{g} / \mathrm{ml} \mathrm{P9}$ for 4 hours at $37^{\circ} \mathrm{C}$ in a humidified chamber containing $5 \% \mathrm{CO}_{2}$. The annexin $\mathrm{V}$ binding assay was performed using the ApoTarget Annexin V FITC Apoptosis Kit (Biosource) and examined with a FACScan Flow Cytometer.

Biotinylation of cell surface proteins. To demonstrate that PIM-1 is expressed on the cell surface, PC3 cells $\left(10^{7}\right)$ were washed twice in cold PBS and incubated with $0.5 \mathrm{mg} / \mathrm{ml}$ Sulfo-NHS-LC-Biotin (Pierce) for 30 minutes at $4{ }^{\circ} \mathrm{C}$ (79). Then the cells were washed once in RPMI and twice in PBS. The cells were lysed and cleared by adding BC3, an anti-MUC1 mAb (IgM subclass), and Protein L Gel (Pierce) to immunoprecipitate BC3 antigen complex (80). The precleared lysates $(200 \mu \mathrm{l})$ were immunoprecipitated using $25 \mu \mathrm{g}$ P9 for 1 hour at $4^{\circ} \mathrm{C}$, followed by adding $25 \mu$ Protein L Gel for 2 hours. The beads were washed 3 times using lysis buffer, resuspended in sample buffer, boiled for 5 minutes, and separated using 12\% SDS-PAGE gel. Then the gel was blotted, detected by Streptavidin-HRP or P9 and anti-mouse Ig-HRP, and visualized as described as below.

Western blot. To examine the effect of anti-PIM-1 mAb on the PIM-1 expression and signal transduction pathway, cancer cells $\left(5 \times 10^{6}\right)$ were treated with P9 for 1, 3, and 6 hours, harvested, washed with ice-cold PBS, and then lysed and sonicated in $0.5 \mathrm{ml}$ lysis buffer containing $20 \mathrm{mM}$ Tris (pH 7.5), 150 mM NaCl, 1 mM EDTA, 1 mM EGTA, 1\% Triton X-100, 2.5 $\mathrm{mM}$ sodium pyrophosphate, $1 \mathrm{mM} \beta$-glycerolphosphate, $1 \mathrm{mM}$ sodium orthovanadate $\left(\mathrm{Na}_{3} \mathrm{VO}_{4}\right), 1 \mu \mathrm{g} / \mathrm{ml}$ leupeptin, and $1 \mathrm{mM}$ PMSF. The lysed samples were separated by gradient $4 \%-12 \%$ SDS-PAGE and transferred onto a PVDF membrane (Amersham Pharmacia Biotech). The blots were blocked with $5 \%$ nonfat dry milk in tris-buffered saline containing $0.1 \%$ tween-20 at room temperature for 1 hour and probed with P9 or cell signaling Abs (New England Biolabs), including anti-phospho-Akt at Ser473, anti-phospho-Bad at Ser112, anti-phospho-Bad at Ser136, anti-Bad, and anti-cleaved caspase-9 at Asp330. Total Akt was probed by Akt1/2 (H136) (Santa Cruz Biotechnology Inc.) Ab. The proteins in the PVDF membranes were visualized using chemiluminescence reagent (PerkinElmer) after adding HRP-labeled secondary Abs.

Anti-PIM-1 mAb binding to PIM-1 localized in subcellular fractions. Cell membrane, nuclear, and cytoplasmic fractions were prepared from DU145 cells by using a cellular fractionation kit (BioChain Institute), separated on $10 \%$ SDS-PAGE, transferred onto membrane, and detected with either anti-PIM-1 Ab (67) or P9. Anti-lamin A (as a nuclear marker) (Biolegend) or anti-actin (as a cytoplasmic marker) (Sigma-Aldrich) and EGFR (as a membrane marker) (Cell Signaling) Abs were used to show the quality of separation of the subcellular fractions.

PIM-1-FLAG construct, transfection, immunofluorescence microscope, and flow cytometry analysis. PIM-1 construct with a FLAG tag located at the C-terminal (PIM-1-FLAG), containing CMV promoter only, was generated from $\mathrm{PBK}-\mathrm{CMV}$ phagemid vector, which was removed of lacZ promoter by digestion of $\mathrm{pBK} / \mathrm{CMV}$ with NheI and SpeI. CHOP cells (derived from Chinese hamster ovary cells stably transfected with poly- oma $\mathrm{T}$ antigen) (81) were chosen for expression of PIM-1-FLAG because they are efficiently transfected in transient assays for expression of cell surface (44). For immunofluorescence assay, transfection was performed using Lab-Tek II Chamber Slide (Nalge Nunc Int.). CHOP cells at exponential growth rate were collected and seeded in 8-chamber slides at a density of $5 \times 10^{3} /$ well or $1 \times 10^{4} /$ well in 6 -well plates. The cells were transfected 24 hours later with $\mathrm{pBK}-\mathrm{CMV}$ vector or $\mathrm{pBK}$-CMV-PIMFLAG using Lipofectamine 2000 (Invitrogen) according to the manufacturer's instruction. Cells on Chamber slides were washed with PBS 48 hours after transfection, fixed with cold acetone, and incubated with anti-FLAG mAb M2 (Sigma-Aldrich) and mAb P9, respectively, which was then followed by incubation with FITC-conjugated anti-mouse Abs (Chemicon) and examination by immunofluorescence microscope. Transfected cells in 6-well plates were collected and incubated with Abs as described above for flow cytometric analysis.

Immunoprecipitations. TRAMP-C1 prostate cancer cells were treated with or without $25 \mu \mathrm{g} / \mathrm{ml} \mathrm{mAb}$ P9 for 3 and 6 hours, respectively, and then were harvested, washed twice in cold PBS, lysed in lysis buffer, and cleared by adding IgM and Protein L Gel (Pierce) (80). The precleared lysates (200 $\mu \mathrm{l}$ ) were immunoprecipitated using $\mathrm{P} 9$ or anti-Hsp90 Abs (BD Biosciences) for 1 hour at $4^{\circ} \mathrm{C}$ and were followed by adding $25 \mu 1$ Protein $\mathrm{L}$ Gel for P9 or Protein G-Agarose (Sigma-Aldrich) for Hsp90 Ab immunocomplexes for 2 hours at $4{ }^{\circ} \mathrm{C}$ using a rotary suspension mixer (Ratek Instruments Pty Ltd.). The beads were washed 3 times using lysis buffer, resuspended in sample buffer, and boiled for 5 minutes before separation on 12\% SDSPAGE gel. The gel was blotted as described above and detected by P9, antiHsp90, or rabbit anti-PIM-1 Abs.

PIM-1 expression knockdown using double strand siRNA. Prostate cancer DU145 cells were transfected with the synthetic siRNA [sense, r(ACAUUU ACAACUCAUUCCA)dTdT, and antisense, r(UGGAAUGAGUUGUAAAU GU)dTdG] targeting human PIM1 5'-CAACATTTACAACTCATTCCA-3', using HP Validated siRNA transfection reagents following the manufacturer's instruction (QIAGEN). The DU145 cells were also transfected with AllStarts Negative siRNA (QIAGEN) as a control. The cells were harvested at 66,72 , or 78 hours, respectively, after transfection for Western blot, flow cytometry, or trypan blue exclusion analysis.

Antitumor activity of PIM- $1 \mathrm{mAb}$ in vivo. C57BL/6 (H2 $\left.{ }^{\mathrm{b}}\right)$ and SCID mice (10-12 weeks old) were obtained from the Animal Resources Centre, Western Australia, and maintained under specific-pathogen free conditions for the studies. All animal experiments were approved by Animal Ethics Committee, Austin Health, Heidelberg, Australia. Human prostate cancer DU145 cells $\left(1 \times 10^{7}\right)$ were inoculated subcutaneously in SCID mice. Eight hours later, the mice received $0.5 \mathrm{mg}$ P9, followed by $0.25 \mathrm{mg}$ intraperitoneally, twice per week, for 6 injections. To examine antitumor efficacy of P9 on an established tumor of TRAMP-C1 $\left(\mathrm{H} 2^{\mathrm{b}}\right)$ cells $\left(5 \times 10^{6}\right)$ in the syngeneic graft model, C57BL/6 mice were treated with P9 (0.5 mg per mouse) intraperitoneally on day 6 , when the tumor sizes reached a mean of $50 \mathrm{~mm}^{3}$, followed by $0.25 \mathrm{mg}$ P9 twice a week, for 4.5 weeks. Tumors were measured at 2 - to 4 -day intervals with a caliper, and tumor size was calculated (length $\times$ width $\times$ height) as described previously (78).

Statistics. A 2-way ANOVA was used for substantiating 2 agents acting synergistically when eliciting a biological response (48-51). The effect of combining anti-PIM-1 mAb and chemotherapeutic agents cisplatin or epirubicin was analyzed by using the 2-way ANOVA, conducted using GraphPad Prism Version 4.0 (GraphPad Software Inc.), based on the results of $\left[{ }^{3} \mathrm{H}\right]$-thymidine incorporation on DU145 cancer cells when the cells were tested by (a) low concentrations of anti-PIM-1 mAb alone; (b) various concentrations of cisplatin or epirubicin alone; or (c) over a range of concentrations of anti-PIM-1 mAb and each drug together; and (d) neither treatment (i.e., the control). $P$ values of less than 0.05 were considered to 
be significant for synergistic interaction for each concentrations of $\mathrm{mAb}$ and drugs alone and in combination (48). In addition, Mann-Whitney nonparametric $U$ test was used to compare the tumor sizes in the mice treated with $\mathrm{mAb}$ and PBS.

\section{Acknowledgments}

We gratefully acknowledge the support from Association of International Cancer Research, United Kingdom (03-121), CASS Foundation, Australia (SM/04/374), National Breast Cancer Foundation, Australia, and NIH grant RO1 CA104470. We thank Ian F.C. McKenzie for his great contribution in the early stage of the study. We also thank M. Wright and B. Loveland for their help with the experiment on PIM-1 cell surface expression. We are especially grateful to M. Sandrin and W.X. Lin for helping us with transfection experiment.

Received for publication July 9, 2007, and accepted in revised form December 3, 2008.

Address correspondence to: Pei Xiang Xing, Cancer Immunotherapy Laboratory, Burnet Institute Incorporating Austin Research Institute, Kronheimer Building, Studley Road, Heidelberg, Victoria 3084, Australia. Phone: 61-3-9287-0676; Fax: 61-3-9287-0600; E-mail: px.xing@burnet.edu.au.
1. Wang, Z., et al. 2001. Pim-1: a serine/threonine kinase with a role in cell survival, proliferation, differentiation and tumorigenesis. J. Vet. Sci. 2:167-179.

2. Bachmann, M., and Moroy, T. 2005. The serine/ threonine kinase Pim-1. Int. J. Biochem. Cell Biol. 37:726-730.

3. Dhanasekaran, S.M., et al. 2001. Delineation of prognostic biomarkers in prostate cancer. Nature. 412:822-826

4. Amson, R., et al. 1989. The human protooncogene product p33pim is expressed during fetal hematopoiesis and in diverse leukemias. Proc. Natl. Acad. Sci. U. S. A. 86:8857-8861.

5. Cuypers, H.T., et al. 1984. Murine leukemia virusinduced T-cell lymphomagenesis: integration of proviruses in a distinct chromosomal region. Cell. 37:141-150.

6. van der Lugt, N.M., et al. 1995. Proviral tagging in E mu-myc transgenic mice lacking the Pim-1 protooncogene leads to compensatory activation of Pim-2. EMBO J. 14:2536-2544.

7. Saris, C.J., Domen, J., and Berns, A. 1991. The pim-1 oncogene encodes two related protein-serine/threonine kinases by alternative initiation at AUG and CUG. EMBO J. 10:655-664.

8. Reeves, R., Spies, G.A., Kiefer, M., Barr, P.J., and Power, M. 1990. Primary structure of the putative human oncogene, pim-1. Gene. 90:303-307.

9. Xie, Y., et al. 2006. The $44 \mathrm{kDa}$ Pim-1 kinase directly interacts with tyrosine kinase Etk/BMX and protects human prostate cancer cells from apoptosis induced by chemotherapeutic drugs. Oncogene. 25:70-78.

10. Muraski, J.A., et al. 2007. Pim-1 regulates cardiomyocyte survival downstream of Akt. Nat. Med. 13:1467-1475.

11. Eichmann, A., Yuan, L., Breant, C., Alitalo, K., and Koskinen, P.J. 2000. Developmental expression of pim kinases suggests functions also outside of the hematopoietic system. Oncogene. 19:1215-1224.

12. Gapter, L.A., Magnuson, N.S., Ng, K.Y., and Hosick, H.L. 2006. Pim-1 kinase expression during murine mammary development. Biochem. Biophys. Res. Com mun. 345:989-997.

13. Moroy, T., Grzeschiczek, A., Petzold, S., and Hartmann, K.U. 1993. Expression of a Pim-1 transgene accelerates lymphoproliferation and inhibits apoptosis in lpr/lpr mice. Proc. Natl. Acad. Sci. U. S. A. 90:10734-10738.

14. Cibull, T.L., et al. 2006. Overexpression of Pim-1 during progression of prostatic adenocarcinoma. J. Clin. Pathol. 59:285-288.

15. Valdman, A., Fang, X., Pang, S.T., Ekman, P., and Egevad, L. 2004. Pim-1 expression in prostatic intraepithelial neoplasia and human prostate cancer. Prostate. 60:367-371.

16. Kim, O., et al. 2004. Synergism of cytoplasmic kinases in IL6-induced ligand-independent activation of androgen receptor in prostate cancer cells. Oncogene. 23:1838-1844.

17. Chiang, W.F., et al. 2006. Up-regulation of a serine- threonine kinase proto-oncogene Pim-1 in oral squamous cell carcinoma. Int. J. Oral Maxillofac. Surg. 35:740-745.

18. Alizadeh, A.A., et al. 2000. Distinct types of diffuse large B-cell lymphoma identified by gene expression profiling. Nature. 403:503-511.

19. Mizuki, M., et al. 2003. Suppression of myeloid transcription factors and induction of STAT response genes by AML-specific Flt3 mutations. Blood. 101:3164-3173.

20. Nieborowska-Skorska, M., Hoser, G., Kossev, P., Wasik, M.A., and Skorski, T. 2002. Complementary functions of the antiapoptotic protein A1 and serine/threonine kinase pim- 1 in the BCR/ABL-mediated leukemogenesis. Blood. 99:4531-4539.

21. Peltola, K.J., et al. 2004. Pim-1 kinase inhibits STAT5-dependent transcription via its interactions with SOCS1 and SOCS3. Blood. 103:3744-3750.

22. Krishnan, N., Pan, H., Buckley, D.J., and Buckley, A. 2003. Prolactin-regulated pim-1 transcription: identification of critical promoter elements and Akt signaling. Endocrine. 20:123-130.

23. Krumenacker, J.S., Narang, V.S., Buckley, D.J., and Buckley, A.R. 2001. Prolactin signaling to pim-1 expression: a role for phosphatidylinositol 3-kinase. J. Neuroimmunol. 113:249-259.

24. Mizuno, K., et al. 2001. Regulation of Pim-1 by Hsp90. Biochem. Biophys. Res. Commun. 281:663-669.

25. Shay, K.P., Wang, Z., Xing, P.X., McKenzie, I.F., and Magnuson, N.S. 2005. Pim-1 kinase stability is regulated by heat shock proteins and the ubiquitinproteasome pathway. Mol. Cancer Res. 3:170-181.

26. Palaty, C.K., et al. 1997. Identification of the autophosphorylation sites of the Xenopus laevis Pim-1 proto-oncogene-encoded protein kinase. J. Biol. Chem. 272:10514-10521.

27. Palaty, C.K., Clark-Lewis, I., Leung, D., and Pelech, S.L. 1997. Phosphorylation site substrate specificity determinants for the Pim-1 protooncogene-encoded protein kinase. Biochem. Cell Biol. 75:153-162.

28. Bullock, A.N., Debreczeni, J., Amos, A.L., Knapp, S., and Turk, B.E. 2005. Structure and substrate specificity of the Pim-1 kinase. J. Biol. Chem. 280:41675-41682.

29. Wang, Z., et al. 2002. Phosphorylation of the cell cycle inhibitor p21Cip1/WAF1 by Pim-1 kinase. Biochim. Biophys. Acta. 1593:45-55.

30. Zhang, Y., Wang, Z., and Magnuson, N.S. 2007. Pim-1 kinase-dependent phosphorylation of p21Cip1/ WAF1 regulates its stability and cellular localization in H1299 cells. Mol. Cancer Res. 5:909-922.

31. Mochizuki, T., et al. 1999. Physical and functional interactions between Pim-1 kinase and Cdc25A phosphatase. Implications for the Pim-1-mediated activation of the c-Myc signaling pathway. J. Biol. Chem. 274:18659-18666.

32. Wang, Z., et al. 2001. Pim-1 negatively regulates the activity of PTP-U2S phosphatase and influences terminal differentiation and apoptosis of monoblastoid leukemia cells. Arch. Biochem. Biophys. 390:9-18.
33. Bhattacharya, N., Wang, Z., Davitt, C., McKenzie, I.F., Xing, P.X., and Magnuson, N.S. 2002. Pim-1 associates with protein complexes necessary for mitosis. Chromosoma. 111:80-95.

34. Bachmann, M., Hennemann, H., Xing, P.X., Hoffmann, I., and Moroy, T. 2004. The oncogenic serine/threonine kinase Pim-1 phosphorylates and inhibits the activity of Cdc25C-associated kinase 1 (C-TAK1): a novel role for Pim-1 at the G2/M cell cycle checkpoint. J. Biol. Chem. 279:48319-48328.

35. Bachmann, M., et al. 2006. The oncogenic serine/ threonine kinase Pim-1 directly phosphorylates and activates the G2/M specific phosphatase Cdc25C. Int. J. Biochem. Cell Biol. 38:430-443.

36. Shirogane, T., et al. 1999. Synergistic roles for Pim-1 and c-Myc in STAT3-mediated cell cycle progression and antiapoptosis. Immunity. 11:709-719.

37. Pircher, T.J., Zhao, S., Geiger, J.N., Joneja, B., and Wojchowski, D.M. 2000. Pim-1 kinase protects hematopoietic FDC cells from genotoxin-induced death. Oncogene. 19:3684-3692.

38. Datta, S.R., et al. 2002. Survival factor-mediated BAD phosphorylation raises the mitochondrial threshold for apoptosis. Dev. Cell. 3:631-643.

39. Yan, B., et al. 2003. The PIM-2 kinase phosphorylates BAD on serine 112 and reverses BAD-induced cell death. J. Biol. Chem. 278:45358-45367.

40. Aho, T.L., et al. 2004. Pim-1 kinase promotes inactivation of the pro-apoptotic Bad protein by phosphorylating it on the Ser112 gatekeeper site. FEBS Lett. 571:43-49.

41. Macdonald, A., et al. 2006. Pim kinases phosphorylate multiple sites on Bad and promote 14-3-3 binding and dissociation from Bcl-XL. BMC Cell Biol. $7: 1$.

42. Xie, Y., et al. 2008. The 44-kDa Pim-1 kinase phosphorylates BCRP/ABCG2 and thereby promotes its multimerization and drug-resistant activity in human prostate cancer cells. J. Biol. Chem. 283:3349-3356

43. Amaravadi, R., and Thompson, C.B. 2005. The survival kinases Akt and Pim as potential pharmacological targets. J. Clin. Invest. 115:2618-2624.

44. Sasaki, M., Miyosawa, K., Ohkubo, S., and Nakahata, N. 2006. Physiological significance of thromboxane A(2) receptor dimerization. J. Pharmacol. Sci. 100:263-270.

45. Petrioli, R., et al. 2002. Weekly epirubicin in patients with hormone-resistant prostate cancer. Br. J. Cancer. 87:720-725.

46. Cohen, S.M., and Lippard, S.J. 2001. Cisplatin: from DNA damage to cancer chemotherapy. Prog. Nucleic Acid Res. Mol. Biol. 67:93-130.

47. Kim, R., et al. 2006. Regulation and interplay of apoptotic and non-apoptotic cell death. J. Pathol. 208:319-326.

48. Slinker, B.K. 1998. The statistics of synergism. J. Mol. Cell. Cardiol. 30:723-731.

49. Zhang, P., et al. 2005. Synergistic down-regulation of telomerase by all-trans retinoic acid and antisense oligonucleotide in oral squamous cell carci- 
noma cell line (Tca8113). Oral Oncol. 41:909-915.

50. Hu, X.F., Martin, T.J., Bell, D.R., de Luise, M., and Zalcberg, J.R. 1990. Combined use of cyclosporin A and verapamil in modulating multidrug resistance in human leukemia cell lines. Cancer Res. 50:2953-2957.

51. Hu, X.F., Li, J., Yang, E., Vandervalk, S., and Xing, P.X. 2007. Anti-Cripto Mab inhibit tumour growth and overcome MDR in a human leukaemia MDR cell line by inhibition of Akt and activation of JNK/SAPK and bad death pathways. Br. J. Cancer. 96:918-927.

52. Zalcberg, J.R., et al. 1994. Cellular and karyotypic characterization of two doxorubicin resistant cell lines isolated from the same parental human leukemia cell line. Int. J. Cancer. 57:522-528.

53. Vermes, I., Haanen, C., Steffens-Nakken, H., and Reutelingsperger, C. 1995. A novel assay for apoptosis. Flow cytometric detection of phosphatidylserine expression on early apoptotic cells using fluorescein labelled Annexin V. J. Immunol. Methods. 184:39-51.

54. Qian, K.C., et al. 2005. Structural basis of constitutive activity and a unique nucleotide binding mode of human Pim-1 kinase. J. Biol. Chem. 280:6130-6137.

55. Lin, J., Adam, R.M., Santiestevan, E., and Freeman, M.R. 1999. The phosphatidylinositol 3'-kinase pathway is a dominant growth factor-activated cell survival pathway in LNCaP human prostate carcinoma cells. Cancer Res. 59:2891-2897.

56. Graff, J.R., et al. 2000. Increased AKT activity contributes to prostate cancer progression by dramatically accelerating prostate tumor growth and diminishing p27Kip1 expression. J. Biol. Chem. 275:24500-24505.

57. Sato, S., Fujita, N., and Tsuruo, T. 2000. Modulation of Akt kinase activity by binding to Hsp90. Proc. Natl. Acad. Sci. U. S. A. 97:10832-10837.

58. Solit, D.B., Basso, A.D., Olshen, A.B., Scher, H.I., and Rosen, N. 2003. Inhibition of heat shock protein 90 function down-regulates Akt kinase and sensitizes tumors to Taxol. Cancer Res. 63:2139-2144.
59. Holder, S., et al. 2007. Characterization of a potent and selective small-molecule inhibitor of the PIM1 kinase. Mol. Cancer Ther. 6:163-172.

60. Prag, S., et al. 2007. Activated ezrin promotes cell migration through recruitment of the GEF Dbl to lipid rafts and preferential downstream activation of Cdc42. Mol. Biol. Cell. 18:2935-2948.

61. McLaughlin, S., and Murray, D. 2005. Plasma membrane phosphoinositide organization by protein electrostatics. Nature. 438:605-611.

62. Chishti, A.H., et al. 1998. The FERM domain: a unique module involved in the linkage of cytoplasmic proteins to the membrane. Trends Biochem. Sci. 23:281-282.

63. Gasteiger, E., et al. 2003. ExPASy: The proteomics server for in-depth protein knowledge and analysis. Nucleic Acids Res. 31:3784-3788.

64. Chen, R., et al. 2001. Regulation of the PH-domaincontaining tyrosine kinase Etk by focal adhesion kinase through the FERM domain. Nat. Cell Biol. 3:439-444.

65. Fleischer, A., et al. 2004. Bad-dependent rafts alteration is a consequence of an early intracellular signal triggered by interleukin- 4 deprivation. Mol. Cancer Res. 2:674-684.

66. Simons, K., and Toomre, D. 2000. Lipid rafts and signal transduction. Nat. Rev. Mol. Cell Biol. 1:31-39.

67. Liang, H., Hittelman, W., and Nagarajan, L. 1996. Ubiquitous expression and cell cycle regulation of the protein kinase PIM-1. Arch. Biochem. Biophys. 330:259-265.

68. Kamal, A., et al. 2003. A high-affinity conformation of Hsp90 confers tumour selectivity on Hsp90 inhibitors. Nature. 425:407-410.

69. Isaacs, J.S., Xu, W., and Neckers, L. 2003. Heat shock protein 90 as a molecular target for cancer therapeutics. Cancer Cell. 3:213-217.

70. Zhang, Y., Wang, Z., Li, X., and Magnuson, N.S. 2008. Pim kinase-dependent inhibition of c-Myc degradation. Oncogene. 27:4809-4819.

71. Teng, S.C., et al. 2004. Direct activation of HSP90A transcription by c-Myc contributes to c-Myc-induced transformation. J. Biol. Chem. 279:14649-14655.

72. Hammerman, P.S., Fox, C.J., Birnbaum, M.J., and Thompson, C.B. 2005. Pim and Akt oncogenes are independent regulators of hematopoietic cell growth and survival. Blood. 105:4477-4483.

73. Kai, M., et al. 2008. Switching constant domains enhances agonist activities of antibodies to a thrombopoietin receptor. Nat. Biotechnol. 26:209-211.

74. Alessi, D.R., et al. 1996. Mechanism of activation of protein kinase B by insulin and IGF-1. EMBO J. 15:6541-6551.

75. Jacobs, M.D., et al. 2005. Pim-1 ligand-bound structures reveal the mechanism of serine/threonine kinase inhibition by LY294002. J. Biol. Chem. 280:13728-13734.

76. Datta, S.R., et al. 1997. Akt phosphorylation of BAD couples survival signals to the cell-intrinsic death machinery. Cell. 91:231-241.

77. Hoover, D., Friedmann, M., Reeves, R., and Magnuson, N.S. 1991. Recombinant human pim-1 protein exhibits serine/threonine kinase activity.J. Biol. Chem. 266:14018-14023.

78. Xing, P.X., Hu, X.F., Pietersz, G.A., Hosick, H.L., and McKenzie, I.F. 2004. Cripto: a novel target for antibody-based cancer immunotherapy. Cancer Res. 64:4018-4023.

79. Szabo, R., Netzel-Arnett, S., Hobson, J.P., Antalis, T.M., and Bugge, T.H. 2005. Matriptase-3 is a novel phylogenetically preserved membrane-anchored serine protease with broad serpin reactivity. Biochem. J. 390:231-242.

80. Nilson, B.H., Logdberg, L., Kastern, W., Bjorck, L., and Akerstrom, B. 1993. Purification of antibodies using protein L-binding framework structures in the light chain variable domain. J. Immunol. Methods. 164:33-40.

81. Heffernan, M., and Dennis, J.W. 1991. Polyoma and hamster papovavirus large $\mathrm{T}$ antigen-mediated replication of expression shuttle vectors in Chinese hamster ovary cells. Nucleic Acids Res. 19:85-92. 